This item was submitted to Loughborough's Research Repository by the author.

Items in Figshare are protected by copyright, with all rights reserved, unless otherwise indicated.

\title{
The Statistical Downscaling Model - Decision Centric (SDSM-DC): conceptual basis and applications
}

PLEASE CITE THE PUBLISHED VERSION

http://dx.doi.org/10.3354/cr01254

\section{PUBLISHER}

(C) Inter-Research

VERSION

AM (Accepted Manuscript)

\section{PUBLISHER STATEMENT}

This work is made available according to the conditions of the Creative Commons Attribution-NonCommercialNoDerivatives 4.0 International (CC BY-NC-ND 4.0) licence. Full details of this licence are available at: https://creativecommons.org/licenses/by-nc-nd/4.0/

\section{LICENCE}

CC BY-NC-ND 4.0

\section{REPOSITORY RECORD}

Wilby, Robert L., Christian W. Dawson, Conor Murphy, P. O'Connor, and E. Hawkins. 2019. "The Statistical Downscaling Model - Decision Centric (SDSM-DC): Conceptual Basis and Applications”. figshare. https://hdl.handle.net/2134/17684. 


\section{The Statistical DownScaling Model - Decision Centric 2 (SDSM-DC): Conceptual basis and applications}

3

4 Wilby $^{1}$, R.L., Dawson², C.W., Murphy ${ }^{3}$, C., O’Connor ${ }^{3}$, P. and Hawkins ${ }^{4}$, E. 5

$6 \quad{ }^{1}$ Department of Geography, Loughborough University, LE11 3TU, UK

$7 \quad{ }^{2}$ Department of Computer Science, Loughborough University, LE11 3TU, UK

$8 \quad{ }^{3}$ Department of Geography, National University of Ireland Maynooth, Maynooth, Ireland

$9 \quad{ }^{4}$ Department of Meteorology, University of Reading, RG6 6BB, UK

16 Accepted for publication: Climate Research

17 Acceptance date: 18 July 2014

18

19 Corresponding author: Robert Wilby (email: r.l.wilby@lboro.ac.uk) 


\section{Abstract}

22 Regional climate downscaling has arrived at an important juncture. Some in the research

23 community favour continued refinement and evaluation of downscaling techniques within a

24 broader framework of uncertainty characterisation and reduction. Others are calling for

25 smarter use of downscaling tools, accepting that conventional, scenario-led strategies for 26 adaptation planning have limited utility in practice. This paper sets out the rationale and new 27 functionality of the Decision Centric (DC) version of the Statistical DownScaling Model 28 (SDSM-DC). This tool enables synthesis of plausible daily weather series, exotic variables 29 (such as tidal surge), and climate change scenarios guided, not determined, by climate model 30 output. Two worked examples are presented. The first shows how SDSM-DC can be used to 31 reconstruct and in-fill missing records based on calibrated predictor-predictand relationships.

32 Daily temperature and precipitation series from sites in Africa, Asia and North America are 33 deliberately degraded to show that SDSM-DC can reconstitute lost data. The second 34 demonstrates the application of the new scenario generator for stress testing a specific adaptation decision. SDSM-DC is used to generate daily precipitation scenarios to simulate winter flooding in the Boyne catchment, Ireland. This sensitivity analysis reveals the conditions under which existing precautionary allowances for climate change might be insufficient. We conclude by discussing the wider implications of the proposed approach and research opportunities presented by the new tool.

\section{Key words}

42 Downscaling; Climate scenario; Weather generator; Stress test; Data reconstruction; 43 Adaptation 


\section{Introduction}

45

Attitudes are changing about the production and utility of regional climate change scenarios. The notion that climate model output can be used in a deterministic sense to direct adaptation decisions is increasingly hard to defend in the face of recognised uncertainties in global and regional climate modelling - both statistical and dynamical (Pielke Sr \& Wilby 2012, Stakhiv 2011). There are a few cases where downscaled products have been applied, such as establishment of precautionary allowances for flood risk in Australia, Denmark, Germany and the UK (Wilby \& Keenan 2012). However, some believe that climate models are still not yet “ready for prime time” (Kundzewicz and Stakhiv, 2010). Others advocate an assess-riskof policy over predict-then-act framework (Lempert et al. 2004, Weaver et al. 2013).

Conventional uses of downscaling include production of scenarios, data inputs for impacts modelling, evaluation of the consequences relative to present climate, and discussion of appropriate adaptation responses. Typically, large uncertainties attached to climate model scenarios cascade into even larger uncertainties in downscaled regional climate change scenarios and impacts (Figure 1). The decision-maker is then left with a bewildering range of possibilities, and often defaults to "low regret” decisions (World Bank 2012). A few studies use regional downscaling to explore the relative significance of uncertainty components, for example in future snowmelt (Dobler et al. 2012), high (Smith et al. 2014), low (Wilby \& Harris 2006), or mean river flows (Bastola et al. 2011).

The Statistical DownScaling Model (SDSM) was originally conceived as a regional climate change scenario generator to support climate risk assessment and adaptation planning. A meta-analysis of the first decade of published work using SDSM showed that over half the $200+$ studies to date refer to water and flood impacts, often with regards to the production of climate scenarios, benchmarking with other scenario tools, or refinement of downscaling techniques (Wilby \& Dawson 2013). A modest but growing number of studies apply the tool in adaptation planning or climate risk management ${ }^{1}$.

Some assert that downscaling should be used to appraise adaptation options through vulnerability-led rather than scenario-led methodologies (Wilby \& Dessai, 2010). In this 'bottom-up' framework, the scenario is used to evaluate the performance (some say "stress test”) adaptation measures. As such, the scenario does not need to be explicitly tied to a given

\footnotetext{
${ }^{1}$ For a bibliography of SDSM studies see: http://co-public.lboro.ac.uk/cocwd/SDSM/Bibliography.pdf
} 
climate model or ensemble; plausible futures can be described by representative climates or generated from weather sequences using simple narratives of the future (such as "warmer", “drier”, "more variable”) (Whetton et al. 2012). Scenarios are then used to test the sensitivity of the system or decision set, ideally to reveal non-linear behaviours or break-points under prescribed climate-forcing (e.g., Prudhomme et al. 2010, Stakhiv 2011, Brown \& Wilby, 2012, Lempert et al. 2012, Nazemi et al. 2013, Steinschneider \& Brown, 2013; Turner et al., 2014).

Accordingly, this paper describes a suite of tools for producing daily weather series and climate scenarios without explicit use of climate model output. Our Decision-Centric (DC) version of SDSM is built on the premise that downscaled scenarios should be informed by but not determined by climate models. This increases the range of plausible scenarios that can be evaluated in an adaptation context. The new Weather Generator in SDSM-DC also provides tools for in-filling missing data and interrogating local climate information based on re-analysis predictor variables. These functions enable application in data sparse regions and leads to deeper understanding of regional climate systems.

The purpose of this paper is to introduce the new functions of SDSM-DC and to demonstrate their usage with two case studies. The following section describes the technical basis of SDSM-DC as applied to single and multiple sites. We then illustrate how SDSM-DC can be used for data reconstruction in contrasting climate regimes. These analyses address the often asked question about how much data is needed to calibrate the model to achieve a given level of skill. The second worked example shows how SDSM-DC can be used in a 'stress testing' situation. In this case, we refer to the definition of safety margins for flood risk under a changed climate in Ireland. Finally, we identify some of the research opportunities emerging from a 'bottom-up', vulnerability-based paradigm for downscaling.

\section{SDSM-DC}

Earlier versions of SDSM have been described elsewhere (Wilby et al. 2002, 2003, Wilby \& Dawson 2013) but for completeness are brought together here. The tool enables the production of climate change time series at sites for which there are daily observations (the predictand) and re-analysis products describing large-scale atmospheric properties (the predictors) for model calibration. In the vintage version of SDSM, archived General 
105 Circulation Model (GCM) output may then be used to generate scenarios for future decades.

106 The SDSM-DC User is guided through each stage of the downscaling process by a set of

107 screens (Figure 2). These address key functions such as basic quality control and

108 transformations (as required) of input data; predictor variable selection; model set-up and

109 calibration; weather and scenario generation; diagnostics for interrogating model output

110 (summary statistics, frequency and time-series analysis, graphing). The following section

111 reprises the key features of the single- and multi-site versions of SDSM then introduces the

112 new functions of SDSM-DC.

113

\section{$114 \quad 2.1$ Downscaling single sites}

115 SDSM is best described as a conditional weather generator because atmospheric circulation

116 indices and regional moisture variables are used to estimate time-varying parameters

117 describing daily weather at individual sites (e.g., precipitation occurrence or daily mean

118 temperatures). The downscaled process is either unconditional (as with wet-day occurrence or

119 air temperature), or is conditional on an event (as with rainfall amounts).

120 For wet-day occurrence $W_{i}$ there is a direct linear dependency on $n$ predictor variables $X_{i j}$ on 121 day $i$ :

$$
W_{i}=\alpha_{0}+\sum_{j=1}^{n} \alpha_{j} X_{i j}
$$

122 under the constraint $0 \leq W_{i} \leq 1$. Precipitation occurs when the uniform random number $[0,1]$

$123 r \leq W_{i}$. The threshold (mm) for a wet-day varies between locations, depending on the

124 definition of trace rainfalls or precision of measurement. Here we define a wet-day as any day 125 with non-zero precipitation total.

126 When a wet-day is returned, the precipitation total $P_{i}$ is downscaled using:

$$
P_{i}^{k}=\beta_{0}+\sum_{j=1}^{n} \beta_{j} X_{i j}+e_{i}
$$

127 where $k$ is used to transform daily wet-day amounts to better match the normal distribution.

128 Here we apply the fourth root transformation (i.e., $k=0.25$ ) to $P_{i}$. Note that the same 
predictor set is used to downscale $W_{i}$ and $P_{i}$ and that all predictors $v_{i j}$ are standardised with respect to the 1961-1990 mean $\bar{V}_{j}$ and standard deviation $\sigma_{j}$ :

$$
X_{i j}=\frac{v_{i j}-\bar{V}_{j}}{\sigma_{j}}
$$

131 For unconditional processes, such as temperature, there is a direct linear relationship between the predictand $U_{i}$ and the chosen predictors $X_{i j}$ :

$$
U_{i}=\gamma_{0}+\sum_{j=1}^{n} \gamma_{j} X_{i j}+e_{i}
$$

133 The model error $e_{i}$ is assumed to follow a Gaussian distribution and is stochastically

134 generated from normally distributed random numbers and added on a daily basis to the

135 deterministic component. This white noise enables closer fit of the variance of the observed

136 and downscaled distributions, but is known to degrade skill at replicating serial

137 autocorrelation implicit to daily predictor variables. The stochastic process also enables the

138 generation of ensembles of time-series to reflect model uncertainty.

139 All downscaling parameters $\left(\alpha_{j}, \beta_{j}\right.$, and $\left.\gamma_{j}\right)$ are obtained via least squares calibration of the

140 local predictand(s) against regional predictor variables derived from the National Center for

141 Environmental Prediction (NCEP) re-analysis (Kalnay et al. 1996) using data for any period

142 within 1961-2000. Users are advised to calibrate SDSM using data drawn from this period

143 because it is assumed that these decades have relatively high data quality/availability with

144 modest risk of nonstationarity in predictor-predictand relationships due to anthropogenic

145 forcings. Predictands are downscaled separately so any covariance must be conveyed by

146 common predictor variables and/or correlation between predictors. Model testing suggests

147 that this is a reasonable assumption (Wilby et al. 1998).

148 In common with all downscaling methods, SDSM predictor-predictand relationships are

149 assumed to be unaffected by anthropogenic influences during the calibration period, and are

150 applicable to conditions outside the training set. In practice, the parameters of all empirical

151 and dynamical downscaling models are observed to vary over decadal-time scales, not least

152 because of natural variability. Furthermore, the climate effects of land-surface changes

153 cannot be captured by conventional statistical downscaling models (Pielke Sr. \& Wilby 2011).

154 For instance, previous work in the western US suggests that winter snow/ice cover feedbacks 
can lead to lower temperatures than expected by downscaling models (Wilby \& Dettinger 2000). All these caveats undermine the case for applying downscaling in predict-then-act modes.

\subsection{SDSM-DC functionality}

Perhaps the most contentious aspect of SDSM-DC is that climate scenarios are not determined explicitly by climate model output. Rather, the range of the adjustments may be informed by palaeoclimatic evidence, expert judgement, or climate model experiments. Alternatively, the range may be designed to bracket conditions that would stress the target system(s) to failure (Steinschneider \& Brown 2013). These methods represent a marked departure from main-stream downscaling ideology which is wholly contingent upon the realism of future driving variables supplied by climate models. Nonetheless, there is acceptance that even massive climate model ensembles may understate the true uncertainty in regional climate change (Stainforth et al. 2007, Deser et al. 2012). Therefore, tools are needed to generate scenarios that can test adaptation decisions and system vulnerabilities over a much wider (yet still plausible) range of climate variability and change (Steinschneider \& Brown 2013, Brown \& Wilby, 2012, Nazemi et al. 2013).

SDSM-DC enables the User to apply such Treatments to daily predictands. These are Userdefined factors and functions that manipulate the unconditional occurrence process, mean, variance and trend of the original series. Input series may originate from observations ${ }^{2}$ or from output produced by a weather generator (as in Figure 3a) if multiple realisations are required. Four main types of single and multiple treatments are described below.

\subsubsection{Occurrence}

In the following explanation we refer to precipitation as an example manipulation of event occurrence. However, this treatment might apply to any other phenomena with zero and nonzero values (such as sunshine hours). For precipitation the event threshold might be any nonzero total. In this case, the percentage change entered represents the amount by which event frequency should change. For example, a value of $10 \%$ applied to rainfall series would

\footnotetext{
${ }^{2}$ For sample input data, predictor variables and parameter file see: http://co-public.lboro.ac.uk/cocwd/SDSM/sdsmmain.html
} 
increase the number of rain days by $10 \%$; a value of $-20 \%$ would reduce the number of wetdays by a fifth (Figure 3b).

When increasing event frequencies, new wet-days are not generated randomly across the entire range of the series but are weighted according to the baseline occurrence profile. This ensures that (for precipitation occurrence) wet months remain generally wetter than dry months and vice versa. This process involves four stages. First, input series are analysed to determine the frequency of events in each month (e.g., January 16\%; February 20\%, etc.). Second, a random month is selected based on the overall likelihood of occurrence (in this case, February would have a slightly higher chance of being selected than January). Third, a random non-event (dry) day in this month is selected from the concatenated series. Fourth, in order to convert this dry day into a wet day an appropriate event magnitude (wet-day amount) must be determined. This is achieved by sampling a non-zero event from the month. Steps two to four are then repeated until the required percentage change in rain days has been achieved.

Removal of events from the series operates in a similar way to the process outlined above. As before, the series is first analysed to determine the monthly occurrence profile. This likelihood is used to weight the chance of removing an event: those months with the greatest frequency of zero days are most likely to lose a non-zero event. A non-zero day is randomly selected and then removed from that month (anywhere within the entire series) by replacing it with the event threshold value. This process is repeated until the required percentage of events has been achieved.

The above processes are conditionally stochastic since addition or removal of events is weighted by monthly event frequencies, but individual days are randomly changed within months. This effectively amplifies the initial seasonality of event occurrence. Alternatively, the User can prescribe the change in occurrence for each month by setting the target likelihood profile. In this case, SDSM-DC then calculates whether to randomly add or remove events from each month in turn (across the entire series). In cases where a month has no events, magnitudes are sampled from adjacent months.

Stochastically adding or removing events from a series can affect the mean of the series. If the user wishes to preserve the initial mean despite adjusting the occurrence process, SDSMDC scales the final series such that the overall total is the same as pre-treatment. SDSM-DC stores the event total for the series before the occurrence process is manipulated. The model 
then calculates how much the final series needs to be adjusted in order to preserve this original total. For example, under this set-up, reducing the frequency of events by $10 \%$ would necessitate scaling the remaining non-zero events by $10 \%$ to preserve the pre-treatment mean.

\subsubsection{Mean}

221 The mean treatment enables adjustments to individual daily values by the chosen amount. For

222 a conditional process this treatment is only applied to values above the event threshold (for example, non-zero rainfall amounts). The treatment may be applied either as a factor (such as

224 for precipitation) or by addition (such as for temperature). Note that this also affects other properties of the series including the maximum, quantile distribution, and variance.

\subsubsection{Variance}

228 In order to change the variance and preserve the coefficient of variation (mean divided by standard deviation) only the mean need be scaled (see above). Otherwise, for an unconditional process, the mean is first removed from each value then each data point is multiplied by the square root of the required percentage change in variance. The mean is then added back to the result thereby increasing the variance by the desired amount overall and leaving the mean unchanged. This treatment is summarised as:

$$
U_{m}=\left[\left(U_{i}-\bar{U}\right) *(\sqrt{1+r})\right]+\bar{U}
$$

234 where $U_{m}$ is the transformed value, $U_{i}$ is the original value, $\bar{U}$ is the mean of the series, and $r$ 235 is the change entered by the user $(0 \leq r \leq 1)$. This simple procedure cannot be applied to 236 highly skewed distributions (such as wet-day amounts) because the treatment would yield 237 negative values. In this case, the variance treatment is applied after a Box-Cox transformation 238 (Hinkley 1977, Sakia, 1992):

$$
\begin{array}{ll}
U_{m}=\left(U_{i}^{\lambda}-1\right) / \lambda & \text { where } \lambda \neq 0 ; \\
U_{m}=\ln \left(U_{i}\right) & \text { where } \lambda=0 ;
\end{array}
$$

241 where $\lambda$ lies in the range $[-5,+5]$ and is set to minimise the skewness of the distribution of $U_{m}$. 242 SDSM-DC determines $\lambda$ via iteration until skewness is minimised. In order to evaluate the 
243 effectiveness of the transformation for each $\lambda$ Hinkley's (1977) nonparametric measure of symmetry is applied, $d_{I Q R}$. This does not depend on knowledge of the underlying distribution and may be computed using either the standard deviation or inter-quartile range as the denominator:

$$
d_{I Q R}=\frac{(\text { mean }- \text { median })}{\text { inter_quatile range }}
$$

247 The inter-quartile range is used in preference to the standard deviation in SDSM-DC because 248 the latter tends to drive values of $d$ towards zero for larger values of $\lambda$. As the algorithm employed by SDSM-DC is iterative, the standard deviation may well result in large (positive or negative) values of $\lambda$ being selected which by no means minimise the skewness of the data. Conversely, $d_{I Q R}$ provides similar $\lambda$ value as $d_{S D}$ but does not suffer from convergence as values increase and decrease.

253 Having transformed the series it is now possible to apply the factor to achieve the required variance inflation as with normally distributed data. This is not straightforward as there is no direct relationship between the required variance transformation and the Box-Cox transformed data. Therefore, SDSM-DC applies an iterative approach to determine an appropriate value of $r$. For increased variance $r$ ranges from 0 to a maximum of value of 0.3 ; for decreases $r$ ranges from 0 to a minimum value of -0.5 . Through iteration, SDSM-DC derives an appropriate value of $r$ to achieve the intended variance treatment, such as $+50 \%$ (Figure 3c).

\subsubsection{Trend}

263 SDSM-DC allows three types of trend to be applied to a series: linear, exponential or logistic.

264 A linear trend simply adds (or subtracts) the value entered at each annual increment, scaled 265 within years by Julian day number. For example, 10 would add values from 0 to 10 in the first year, 10 to 20 in the second year, 20 to 30 the following year, etc. For a calendar year each day has added 10/365.25 multiplied by the Julian day number.

For a conditional process, event values are adjusted multiplicatively. For example, if the factor is 5, events in the first year are increased by 0 to $5 \%$ linearly (for days 1 to 365); then by $5 \%$ to $10 \%$ in the second year; and so forth. In this case, the first day would be 
approximately unchanged; a value in the middle of the year would be increased by 2.5\%; and a value at the end of the year by $5 \%$.

Exponential and logistic trends are applied across the entire range of the series, rather than annually as in the linear treatment. An exponential trend adds (or subtracts) an exponential function across the entire range of the data. For example, entering +5 would add between 0 (for the first data point) to +5 (for the final data point) with intervening values scaled exponentially between these end-points (Figure 3d). For a conditional process the treatment is multiplicative rather than additive. For example, +10 would result in exponential scaling by 1 to 1.10 between the first and last non-zero value in the series.

The logistic trend applies an S-shaped function by addition of the chosen value between the first and last points of the unconditional series. For a conditional process the change is multiplicative rather than additive. For example, 5 results in events being scale by 1 to 1.05 across the full length of the series following the logistic curve. The logistic function is useful for introducing step changes into generated series.

\subsubsection{Multiple treatments}

Treatments can be implemented in isolation or combination to create more complex transformations of the series. If the latter, treatments are applied by SDSM-DC in fixed order (Occurrence, Mean, Variance and Trend). For instance, it is possible to adjust the occurrence, by say $-20 \%$, whilst preserving the mean annual precipitation total (Figure 3e). In this case, the generated series would have fewer wet-days but with greater mean intensity. More elaborate scenarios can be produced by simultaneously changing the occurrence, variance and trend (Figure 3f). These complex treatments might be applied to mimic a specific scenario, or to explore known system vulnerabilities. However, the task of interpreting associated impacts becomes much more demanding. Hence, most cases where synthetic series have been used for stress testing are uni- or two-dimensional (e.g., Prudhomme et al. 2010; Nazemi et al., 2013, Steinschneider \& Brown, 2013). 
301

302

303

304

305

306

307

308

309

310

311

312

313

314

315

316

317

318

319

320

321

322

323

324

325

326

327

328

329

330

331

\subsection{Extension to multiple sites}

Although the public domain version of SDSM-DC is for single sites, the basic model can be modified for multi-site applications (following Wilby et al., 2003). This involves two steps. First, a 'marker' series based on daily area averages from several sites (or a single key site) is generated using predictors $X_{i j}$. Second, the area-average is disaggregated to observed daily series recorded at the constituent sites. This is achieved by resampling multi-site values on the date with observed area-average closest to the downscaled area-average. For example, Figure 4 shows that SDSM-DC reproduces the observed range of inter-site correlations for both rainfall and temperature in the Upper Colorado River Basin. Across 76 stations in this catchment, the spatial autocorrelation in daily temperature (mean $r_{\mathrm{obs}}=0.98 ; \mathrm{r}_{\mathrm{SDSM}}=0.98$ ) is found to be more homogeneous than that of precipitation (mean $\mathrm{r}_{\mathrm{obs}}=0.72$; $\mathrm{r}_{\mathrm{SDSM}}=0.69$ ).

Since actual patterns of values are re-sampled by SDSM-DC, both the area average of the marker series and the spatial covariance of the multi-site array are preserved (Wilby et al. 2003, Harpham \& Wilby 2005). Area averages are favoured over single site marker series because there is less risk of employing a non-homogeneous or non-representative record, and predictability is generally increased (because of larger signal-to-noise ratio). As with other resampling methods, the maximum daily value generated cannot exceed the maximum daily amount in the observations without invoking the treatments described above.

\section{Worked example 1: Data reconstruction}

Many of the regions that are most vulnerable to climate variability and change are also the most data sparse. For example, major data gaps exist in the Congo basin, Sahel, central Asia, and Amazon basin. One solution is to support intensive field campaigns (such as the EU African Monsoon Multidisciplinary Analysis [AMMA]) to collect data on poorly understood processes or climate regimes, especially in the Tropics. An alternative strategy is to locate, rescue, digitize, archive and share historic climate data that may be held only as paper or physical copies (as is the mission of the International Environmental Data Rescue Organization [IEDRO]). A third way is to synthesize or infill missing data using a stochastic weather generator. In the following application SDSM-DC is used to reconstruct daily temperature and precipitation series and to demonstrate the trade-off between model skill and information content of available data. 


\subsection{Strategies for weather simulation}

334 There are broadly three main approaches to stochastic weather generator calibration. The most conventional way involves tuning model parameters against available series for precipitation occurrence, then dependent variables such as rainfall amount, temperature, sunshine duration and so forth (Wilks \& Wilby 1999). The resulting model replicates important properties of the data (such as wet-day frequencies and amounts, wet- and dry-spell durations, and covariance amongst variables) or can be used to synthesize much longer series for analysis of extreme events. More sophisticated mixture-model variants can be tuned to simulate low-frequency behaviour of annual to multi-decadal time-scales. Such tools have found important applications in hydrologic design and crop-modelling, but are not suited for data reconstruction because of their stochastic outputs.

344 Others apply weather generators based on parameters (e.g., rainfall occurrence or the alpha and beta parameters of the gamma distribution) that have been prepared from gridded data (e.g., Semenov et al., 2010, 2013) or interpolated from sites where such data exist to locations where they do not (e.g., Camberlin et al. 2014, Semenov \& Brooks 1999). In some cases, landscape properties such as local slope aspect, distance from coast and altitude are extracted from digital elevation models (e.g., the $1 \mathrm{~km}$ resolution Shuttle Radar Topography Mission of the US Geological Survey) to explicitly account for topographic controls via weighted local regressions (e.g., Wilby \& Yu 2013). Such techniques are particularly helpful for estimating weather generator parameters in regions of complex topography but are not so well suited to repairing or infilling partial series.

354 This is where SDSM-DC potentially offers hope: observed (NCEP) predictor-predictand relationships constructed for each calendar month, season, or series as a whole can be used to estimate values on days for which there are no data, or for independently testing suspect values. If it can be assumed that other (non-climatic) forcings are constant, the main practical questions become how much data are needed for reconstruction, and what are the expected uncertainty bounds for reconstructed series? Both aspects are explored below using experiments in which daily series have been deliberately degraded in order to emulate SDSM-DC capabilities under realistic 'field conditions'. 


\subsection{Minimum data requirements}

364 The effect of reducing daily data availability is demonstrated using contrasting sites:

365 Charlottetown on Prince Edward Island, Canada and Tunis in Tunisia (for temperature);

366 Addis Ababa, Ethiopia and Chang wu, China (for precipitation). In each case, the length of

367 observations presented for model calibration was varied between $10 \%$ and $100 \%$ of the

368 available record (equating to about 4 to 40 years of data). Individual days or blocks of years

369 were randomly removed to represent situations in which data records might be patchy or

370 where longer sequences of data are missing. SDSM-DC skill at reproducing the artificially

371 removed days was assessed using the Root Mean Squared Error (RMSE) for temperature; the

372 proportion correct wet-day occurrence (PCW); and the non-parametric Kolmogorov-Smirnov

373 (KS) $D$-statistic to test similarity of wet-day amount distributions.

374 Distributing “lost” data via missing year blocks yielded marginally larger RMSEs in

375 temperature reconstructions than random data gaps, but only for records less than 10 years

376 (Figure 5). This is because the random data reduction might still sample information content

377 for extreme periods or on trends within the series that are otherwise missed when whole year

378 blocks are removed. Both sets of results suggest that beyond 20 years of calibration data there

379 is little reduction in RMSEs for temperature. A similar pattern emerges for precipitation

380 occurrence with the most dramatic reduction in PCW for calibration sets less than 10 years

381 (Figure 6). However, unlike temperature, there appears to be little difference between data

382 degraded by random or block omission. In both cases, the presence or absence of a wet-day

383 (non-zero precipitation) is simulated correctly on average $\sim 75 \%$ of the time.

384 Ability to reproduce wet-day amount distributions was assessed by comparison of cumulative

385 distributions (Figure 7) and the D-statistic (Figure 8). These reveal that the assumed fourth

386 root distribution provides a fair approximation of observed wet-day amounts at both sites,

387 particularly for occurrence of days $>30 \mathrm{~mm}$. The distribution of downscaled wet-day amounts

388 appears to be robust to data reduction until very low levels (10\%) of information are available

389 for model calibration whether random days or years are removed. The type of data reduction

390 is less important for Addis Ababa (Figures 7a and 7b) than for Chang wu (Figures 7c and 7d)

391 because even the initial data set for the former site is partially fragmented.

$392 D$-statistics show little change in ensemble median but variance in the metric grows with

393 increasing levels of data reduction, most notably at Addis Ababa (Figure 8). For this site,

394 model skill at reproducing wet-day amounts is resistant to $10 \%$ random data loss. At Chang 
395

396

397

398

399

400

401

402

403

404

405

406

407

408

409

410

411

412

413

414

415

416

417

418

419

420

421

422

423

424

425

wu, where initial data quality is superior, the $D$-statistic is largely unchanged even after $80 \%$ reduction (by random day removal). The instability of the $D$-statistic for large data reduction at Addis Ababa is due to the diminished number of wet days available for downscaling parameter estimation within individual months. For example, with $90 \%$ data reduction there are fewer than 10 wet-days for model calibration in December. Large $D$ can then arise when the stochasticity of the downscaling algorithm generates unexpectedly large wet-day amounts (as in Figure 7d). Likewise, small $D$ may occur in a large ensemble when the small number of generated wet-days closely matches observations by chance.

With diminished samples of observed wet-day amounts there is larger uncertainty in parameter estimates and proportionately greater influence of any extreme event(s) captured in the sub-set. Figure 8a suggests that $~ 30$ events are needed to obtain stable wet-day parameters for a given month. Moreover, choice of distribution (whether exponential, longnormal, fourth root, gamma, etc.) may be as important as the amount of data available for model calibration. The ramifications for minimum record lengths are most significant for semi-arid and hyper-arid regions where there may be very few wet-days even when there are many years of record, or when data are stratified by season rather than by calendar month. Conversely, as Figure 6 shows, wet-day occurrence estimates are relatively robust to variations in record length and data gaps.

\subsection{Reconstructed time-series}

SDSM-DC was used to reconstruct daily temperature and precipitation series at the same sites as above. Models were fitted to all available data but assessed against metrics that were not applied in calibration, including extreme temperatures and annual precipitation totals. An ensemble of 20 daily series was produced in each case using NCEP predictors for the period 1961-2000. Figures 9a and9b show that SDSM-DC provides a close approximation of observed annual mean ( $\mathrm{r}=0.87)$ and maxima ( $\mathrm{r}=0.91)$ temperatures at Prince Edward Island and Tunis respectively. In both cases, the observations lie within the ensemble range of the downscaled series for the majority of years. The correlation between observations and downscaled series was also high for the annual frequencies of cold $(\mathrm{r}=0.76)$ and hot $(\mathrm{r}=0.91)$ days (Figures 9c and 9d). Again, the majority of the hindcast values lie within the ensemble range. Results for Tunis demonstrate that even when there are strong trends in observations 
the NCEP predictors and downscaling are able to replicate most of the inter-annual and interdecadal variability despite model calibration against daily performance metrics.

SDSM-DC was less skilful at replicating inter-annual variability in wet-day frequencies and totals at Addis Ababa and Chang wu (Figure 10). Although the majority of observed annual totals lie within the ensemble range, the correlation with the ensemble median is weak at Addis Ababa ( $\mathrm{r}=0.36)$ compared with Chang wu ( $\mathrm{r}=0.63)$. Correlations for the annual wetday frequencies are marginally stronger: Addis Ababa ( $\mathrm{r}=0.41)$ and Chang wu ( $\mathrm{r}=0.71)$. Differences in skill between the two sites may reflect the quality and length of data available for calibration: 27 and 40 years respectively. The long-term mean at Addis Ababa is reproduced to within 3\%, but 36\% of observed annuals totals fall outside the ensemble range. Conway et al (2004) note that there is some ambiguity about the location of the site and that the possibility of changes in instrumentation cannot be discounted. Hence, evaluation of the downscaled series remains problematic for this site.

\section{Worked example 2: Stress testing}

In this application SDSM-DC is used to stress-test adaptation decisions for local flood risk management (O’Connor, 2013). By focusing on a specific question rather than the traditional "predict-then-act" approach the application can be categorised as a "bottom-up" approach to adaptation (Brown \& Wilby, 2012). First, the option is described. Second, an impact model is calibrated for the system in question. Third, the scenario generator tool in SDSM-DC is used to construct the inputs for the impact model, and then construct a response surface showing the sensitivity of the system under a wide range of conditions. Finally, results obtained from a given climate model ensemble (such as CMIP3 or CMIP5) may be mapped onto the sensitivity surface to indicate likelihoods based on current knowledge.

\subsection{Identifying the adaptation question or concern}

In adapting to assumed increases in flood risk in Ireland, the Office of Public Works (OPW), the agency responsible for flood risk management, advocate precautionary allowances in design of flood defences (OPW 2009). Under this guidance an allowance of $20 \%$ on design peak flows is recommended under a mid-range future scenario, with a $30 \%$ allowance under 
456

457

458

459

460

461

462

463

464

465

466

467

468

469

470

471

472

473

474

475

476

477

478

479

480

481

482

483

484

485

a high-end future scenario. Note that OPW chose not to tie these allowances explicitly to any emissions or climate model scenario.

The value chosen for the precautionary allowance has far-reaching consequences. If too low, there is a danger of maladaptation and failure to protect lives, livelihoods and critical infrastructure; if too high, the cost of flood defences may be prohibitive or outweigh the intended benefits. Authorities have to weigh up these costs and benefits in the context of uncertainty about climate change impacts. Using an example catchment in east Ireland, SDSM-DC was used to explore the sensitivity of a 1-in-100 year design flood, to changes in key precipitation parameters.

\subsection{Developing an impact model for the chosen system}

The Boyne at Slane Castle in east Ireland has a catchment area of $2460 \mathrm{~km}^{2}$, average annual precipitation 897 mm (1952-2009), Base Flow Index (BFIsoils) 0.69, and an undulating landscape dominated by pasture. The conceptual rainfall-runoff model HYSIM (Manley 2006) was used to simulate streamflow within the catchment. The model has modest data requirements and has been applied previously in Ireland (e.g., Harrigan et al. 2014, Murphy et al. 2006, Bastola et al. 2012). Daily precipitation for three rainfall stations and potential evapotranspiration for the period 1952-2009 were obtained from Met Eireann, while daily streamflow for a gauge at Slane Castle was obtained from the OPW for the same period.

We recognise that HYSIM adds uncertainty due to non-uniqueness of model parameters (Murphy et al. 2006), but apply a single behavioural parameter set for illustrative purposes. Emphasis is placed on characterising uncertainties from GCMs and emission scenarios, given their large contribution to overall uncertainty in local impacts (e.g. Dobler et al. 2012, Wilby \& Harris 2006). HYSIM was trained on daily flows for the period 1981-1995 and verified for the period 1996-2007. Nash-Sutcliffe (NS) (Nash and Sutcliffe 1970) scores of 0.87 and 0.88 were derived for the full training and verification periods respectively, while NS scores of 0.80 and 0.90 for winter (DJF) flows were obtained for training and verification periods respectively, indicating good model performance (Figure 11). To examine changes in flood events the Generalised Logistic (GL) distribution was fitted to annual winter maximum flood series simulated using original and perturbed precipitation series (Hosking and Wallis 1997). 


\subsection{Generating the impact model inputs}

488 SDSM-DC was used to derive a response surface representing the sensitivity of changes in 489 the design (1-in-100 year) flood to prescribed changes in precipitation. The scenario generator function in SDSM-DC was used to perturb observed catchment area-average rainfall to produce daily rainfall series without explicit use of climate model inputs. Changes in rainfall are expected to influence flooding through changes in seasonal wet-day occurrence and amounts. Wide ranges of change for these precipitation attributes were employed to construct bounds within which to perturb observed precipitation. Only winter (DJF) changes are reported here for illustrative purposes.

The sensitivity domain for precipitation parameters was informed by the projections of the Coupled Model Intercomparison Project CMIP3 for the nearest grid box, together with previous impacts assessments for Irish catchments (e.g. Bastola et al. 2012; Murphy \& Charlton 2006). Changes in mean winter rainfall total ranging between -30 and $+30 \%$ and changes in the occurrence of winter wet days (amounts $>0.1 \mathrm{~mm}$ ) between -20 and $+20 \%$ were sampled at 5\% increments and applied to the observed rainfall series (1952-2009). Changes in the likelihood of wet-day occurrence and amounts were applied simultaneously so, for example, $-20 \%$ likelihood of rainfall with $+10 \%$ winter total yields an increase in mean wet-day amounts. Preserving winter totals while adjusting occurrence allows sensitivity to changes in intensity to be explored. Note that these treatments are specific to evaluation of flood risk; sensitivity analysis of other characteristics such as drought would imply alternative treatments to precipitation and potentially evapotranspiration.

\subsection{Constructing the response surface and mapping climate projections}

510 Perturbed rainfall series were input to HYSIM model to explore the sensitivity of the design

511 flood to changes in rainfall properties with results visualised in the form of a response surface

512 (Figure 12). PE was held constant at observed values given low losses during winter months.

513 The 1-in-100 year flood was found to be sensitive to changes in both mean rainfall amounts

514 and changes in the number of wet days. For the ranges of precipitation parameters

515 considered, changes in the magnitude of the 1-in-100 year flood span -40 to $+120 \%$.

516 Even very modest changes in mean rainfall amounts (when combined with reduced wet day 517 occurrence) result in large changes in modelled flood magnitude, delivering rainfall in greater 
518

519

520

521

522

523

524

525

526

527

528

529

530

531

532

533

534

535

536

537

538

539

540

541

542

543

544

545

546

547

548

549

daily amounts and resulting in elevated flood peaks. Even reductions of winter mean rainfall by $10 \%$, when coupled with reductions in the number of wet days by $15 \%$, result in changes in flood magnitude approaching the medium range scenario design allowance of an additional $20 \%$. With no change in wet day occurrence increases in winter mean rainfall of above $5 \%$ result in changes in flood magnitude approaching $20 \%$. The results highlight the sensitivity of flooding within this catchment - not just to changes in rainfall amounts, but to how changes in rainfall amounts are distributed through time. Such sensitivities are moderated by physical catchment properties defining the rainfall-runoff response and will vary on a catchment by catchment basis.

Climate change scenarios were then mapped onto the sensitivity response surface to examine risk of exceedence of the precautionary allowances (Figure 13). The exemplar climate change scenarios are regionalised outputs from 17 GCMs forced with three (A1B, A2 and B1) SRES emissions scenarios from the Coupled Model Intercomparison Project CMIP3 (Bastola et al. 2012). A change factor method based on monthly output from GCMs was used to infer changes in the parameters of a weather generator related to both the magnitude and occurrence of precipitation and was employed to derive regional scenarios for synoptic rainfall stations in Ireland (Bastola et al. 2011). Here 50 realisations of precipitation (based on sampled change factors from GCMs) under each emissions scenario were used to represent uncertainty in future scenarios. For each realisation percent changes in mean winter precipitation amounts and occurrence were derived relative to control simulations for the period 1961-1990. These are then plotted onto the sensitivity response surface, represented as a contour plot, for three future time periods (Figure 13).

Based on the above sensitivity analysis it is concluded that flood defences with a short design life (i.e. to the 2020s) with medium-range allowance of $20 \%$ are likely to be adequate for the Boyne catchment, but some scenarios under the A1B and B1 emissions fall close to the limit of this allowance. However, given that most hard engineering defences have a design life in excess of 50 years, particularly when designed for extremes with a low recurrence interval (such as 1-in-100 year flood) this is unlikely to be the case for the 2050s and beyond. By the 2050s (2040-69) and especially by the 2080s (2070-99) a higher proportion of scenarios exceed the medium range allowance of $20 \%$, under all emissions scenarios. By the 2080s a number of projections under the A1B and A2 emissions scenario exceed even the high range allowance of $30 \%$. 
550 In summary, this case study reveals potential limitations in the medium range allowance to 551 rainfall driven changes in the design flood. By the 2080s there is greater residual risk, 552 indicated by the proportion of scenarios exceeding the $20 \%$ precautionary allowance. Such 553 an 'assess risk of policy' approach allows decision makers to more readily appreciate the

554 sensitivity of the system without explicit reliance on climate models, while the latter can be 555 readily integrated to visualise risk as represented by a large ensemble of climate change 556 scenarios. The approach adopted also facilitates rapid appraisal of such threshold based 557 adaptation decisions and can be extended to national assessments (e.g., Prudhomme et al. 558 2010) or updated as new climate change projections become available.

\section{Conclusions}

561 This paper introduced the latest version of the Statistical DownScaling Model (SDSM) which was engineered with the specific needs of adaptation options appraisal in mind - hence the Decision Centric (-DC) extension. Consistent with other innovations in the downscaling community we are moving away from complete dependence on GCM output for producing regional climate change scenarios. Tools based entirely on weather generator techniques enable synthesis of input variables for impacts modelling and adaptation planning (e.g., Nazemi et al. 2013; Steinschneider \& Brown 2013) but they are not always well-suited to reconstructing and/or infilling historic series. Most weather generators are also unable to synthesize exotic variables (e.g., air quality and urban heat island metrics, wave and tidal surge heights). SDSM-DC addresses these gaps by offering functionality to support data reconstruction and basic weather generation, as well as direct simulation of decision-relevant climate indices (Table 1). Moreover, tests reveal that SDSM performs as well as conventional weather generators such as LARS-WG (see: Hashmi et al., 2011; Hassan et al., 2014). Hence, with these capabilities, it is hoped that SDSM-DC will support decisionmaking in some of the most vulnerable and data sparse regions of the world.

576 Two worked examples were presented to demonstrate some of these capabilities. The first 577 showed that with 10 years of data it is possible to achieve approximately the same level of 578 skill at simulating rainfall occurrence, amounts and temperatures as with 40 years at the 579 chosen sites. The analysis also confirmed that the downscaling is more robust to randomly 580 degraded data throughout a longer record than to lost year blocks. Hence, recovery and 
581

582

583

584

585

586

587

588

589

590

591

592

593

594

595

596

597

598

599

600

601

602

603

604

605

606

607

608

609

610

611

612

digitization of even fragmentary observations may be beneficial and sufficient to allow infilling. Moreover, the stochastic features of SDSM-DC enable confidence limits to be attached to hindcast series so, even where the estimate may be uncertain, the model can at least provide an upper and lower bound.

The second example study showed how SDSM-DC can be used to stress test an adaptation decision - in this case a climate change safety allowance for flood defence schemes. The tool enables arbitrary treatments to be applied to the synthetic series needed for systems modelling. Treatments in the occurrence, mean, variance, and trend of events can be used to elucidate thresholds in the pressure-response. The range of scenarios that are explored may be guided by GCM output but importantly the tool enables exploration of consequences beyond even a multi-model ensemble. Likelihoods can still be attached by overlaying the cloud of model results on the response surface (as in Prudhomme et al. 2010). Moreover, by shifting emphasis from the GCM, the decision-maker is free to consider more holistic narratives that may be pertinent to the decision-making process (including perhaps changes in land cover, fire risk, forest die back and so forth in the case of water resources).

To conclude, the rationale behind SDSM-DC is as much about what the specific tool can do, as how downscaling in general can be used in smarter ways to support adaptation planning. Planned technical enhancements include the ability to manipulate low frequency variability in order to assess multi-season phenomena such as droughts or wet-spells persisting over more than one year. New diagnostics are needed to evaluate expected levels of skill at series reconstruction, perhaps based on more exhaustive cross-validation against whatever data are available. Further exploration of direct downscaling potential is needed, such as for river flows (as in Tisseuil et al., 2010) or other quantities that are typically derived by feeding downscaled climate variables into impact models. Hindcasting performance needs to be tested more thoroughly in a wider range of climate regimes, building on the knowledge base that has been accumulated over the last decade of application. There is also a communitywide need for practical guidance on setting bounds to weather generation for stress testing. Again, this should look beyond the scenario-led framework that would conventionally turn to the latest climate model ensembles but, instead, be guided by knowledge of the vulnerabilities of the system of interest. 


\section{Acknowledgements}

614 The authors thank Dr Tom Matthews for assistance in producing some of the graphics.

615

616 References

617 Bastola S, Murphy C, Fealy R (2012) Generating probabilistic estimates of hydrological 618 response for Irish catchments using a weather generator and probabilistic climate change 619 scenarios. Hydrological Processes, 26, 2307-2321.

620 Bastola S, Murphy C, Sweeney J (2011) The role of hydrological modelling uncertainties in 621 climate change impact assessments of Irish river catchments. Advances in Water 622 Resources, 34, 562-576.

623 Brown C, Werick W, Leger W, Fay D (2011) A decision-analytic approach to managing 624 climate risks: application to the Upper Great Lakes. Journal of the American Water 625 Resources Association 47, 524-534.

626 Brown C, Wilby RL (2012) An alternate approach to assessing climate risks. Eos, 92, 401627403.

628 Camberlin P, Gitau W, Oettli P, Ogallo L, Bois B (2014) Spatial interpolation of daily 629 stochastic generation parameters over East Africa. Climate Research, 59, 39-60.

630 Chu JT, Xia J, Xu CY, Singh VP (2010) Statistical downscaling of daily mean temperature, 631 pan evaporation and precipitation for climate change scenarios in Haihe, China. Theoretical 632 and Applied Climatology, 99, 149-161.

633 Conway D, Mould C, Bewket W (2004) Over one century of rainfall and temperature 634 observations in Addis Ababa, Ethiopia. International Journal of Climatology, 24, 77-91.

635 Cueto ROG, Martinez AT, Ostos EJ (2010) Heat waves and heat days in an arid city in the 636 northwest of Mexico: current trends and in climate change scenarios. International Journal of 637 Biometeorology, 54, 335-345.

638 Deser C, Phillips A, Bourdette V, Teng H (2012) Uncertainty in climate change projections: 639 The role of internal variability. Climate Dynamics, 38, 527-546. 
640 Dobler C, Hagemann S, Wilby RL, Stötter J (2012) Quantifying different sources of 641 uncertainty in hydrological projections at the catchment scale. Hydrology and Earth Systems 642 Science, 16, 4343-4360.

643 Donovan B (2003) An investigation into the relationship between large scale atmospheric 644 variables, wave climate and weather related sea level variations. Unpublished MSc Thesis, 645 Kings College London, 57pp.

646 Hackney CR (2013) Modelling the effects of climate change and sea level rise on the 647 evolution of incised coastal gullies. Unpublished PhD thesis, University of Southampton, 648 203pp.

649 Harpham C, Wilby RL (2005) Multi-site downscaling of heavy daily precipitation occurrence 650 and amounts. Journal of Hydrology, 312, 235-255.

651 Harrigan S, Murphy C, Hall J, Wilby RL, Sweeney J (2014) Attribution of detected changes 652 in streamflow using multiple working hypotheses. Hydrology and Earth System Sciences, 18, $653 \quad 1935-1952$.

654 Hashmi MZ, Shamseldin AY, Melville BW (2011) Comparison of SDSM and LARS-WG for 655 simulation and downscaling of extreme precipitation events in a watershed. Stochastic 656 Environmental Research and Risk Assessment, 25, 475-484.

657 Hassan Z, Shamsudin S, Harun S (2014) Application of SDSM and LARS-WG for 658 simulating and downscaling of rainfall and temperature. Theoretical and Applied Climatology, 659 116, 243-257.

660 Hinkley D (1977) On quick choice of power transformation. Journal of the Royal Statistical 661 Society. Series C (Applied Statistics), 26, 67-69.

662 Holloway T, Spak SN, Barker D, Bretl M, Moberg C, Hayhoe K, Van Dorn J, Wuebbles D 663 (2008) Change in ozone air pollution over Chicago associated with global climate change. 664 Journal of Geophysical Research-Atmospheres, 113, D22306.

665 Hosking JRM, Wallis JR (1997) Regional frequency analysis: an approach based on L666 moments. Cambridge University Press, 224pp.

667 Kalnay E, Kanamitsu M, Kistler R, Collins W, Deaven D, Gandin L, Iredell M, Saha S, 668 White G, Wollen J, Zhu Y, Chelliah M, Ebisuzaki W, Higgins W, Janowiak J, Mo KC, 
669 Ropelewski C, Wang J, Leetmaa A, Reynolds R, Jenne R, Joseph D (1996) The 670 NCEP/NCAR 40-year reanalysis project. Bulletin of the American Meteorological Society, 77, $671437-471$.

672 Kundzewicz ZW, Stakhiv EZ (2010) Are climate models "ready for prime time" in water 673 resources management applications, or is more research needed? Hydrological Sciences 674 Journal, 55, 1085-1089.

675 Lempert R, Nakicenovic N, Sarewitz D, Schlesinger M (2004) Characterizing climate change 676 uncertainties for decision-makers. Climatic Change, 65, 1-9.

677 Lempert R, Sriver RL , Keller K (2012) Characterizing Uncertain Sea Level Rise Projections 678 to Support Investment Decisions. California Energy Commission. Publication Number: CEC679 500-2012-056. RAND, Santa Monica, California.

680 Li Z, Zheng F-L, Liu W-Z (2011) Spatiotemporal characteristics of reference 681 evapotranspiration during 1961-2009 and its projected changes during 2011-2099 on the 682 Loess Plateau of China. Agriculture and Forest Meteorology, 154-155, 147-155.

683 Manley RE (2006) A guide to using HYSIM, R. E. Manley and Water Resource Associates, 684 Ltd.

685 Murphy C, Fealy R, Charlton R, Sweeney J (2006) The reliability of an 'off-the-shelf' 686 conceptual rainfall runoff model for use in climate impact assessment: uncertainty 687 quantification using Latin hypercube sampling. Area 38, 65-78.

688 Nash JE, Sutcliffe JV (1970) River flow forecasting through conceptual models, Part 1: A 689 discussion of principles. Journal of Hydrology, 10, 282-290.

690 Nazemi A, Wheater HS, Chun KP, Elshorbagy A (2013) A stochastic reconstruction 691 framework for analysis of water resource system vulnerability to climate-induced changes in 692 river flow regime. Water Resources Research, 49, 291-305.

693 O’Connor P (2013) Assessment of a decision-centric approach to climate change adaptation. 694 Unpublished Masters thesis. National University of Ireland, Maynooth, 80pp.

695 Office of Public Works (OPW) (2009) Assessment of Potential Future Scenarios. Flood Risk 696 Management Draft Guidance. 
697 Pielke RA Sr., Wilby RL (2012) Regional climate downscaling - what's the point? Eos, 93, $698 \quad 52-53$.

699 Prudhomme C, Wilby RL, Crooks S, Kay AL, Reynard NS (2010) Scenario-neutral approach 700 to climate change impact studies: application to flood risk. Journal of Hydrology, 390, 198701209.

702 Sakia RM (1992) The Box-Cox transformation technique: a review. The Statistician, 41, 169703178.

704 Semenov MA, Brooks RJ (1999) Spatial interpolation of the LARS-WG stochastic weather 705 generator in Great Britain. Climate Research, 11, 137-148.

706 Semenov MA, Donatelli M, Stratonovitch P, Chatzidaki E, Brauth B (2010) ELPIS: a dataset 707 of local-scale daily climate scenarios for Europe. Climate Research, 44, 3-15.

708 Semenov, MA, Pilkington-Bennett S, Calanca P (2013) Validation of ELPIS 1980-2010 709 baseline scenarios using the observed European Climate Assessment data set. Climate 710 Research, 57, 1-9.

711 Smith A, Freer J, Bates P, Sampson C (2014) Comparing ensemble projections of flooding 712 against flood estimations by continuous simulation. Journal of Hydrology, 511, 205-219.

713 Stainforth DA, Downing TE, Lopez RWA, New M (2007). Issues in the interpretation of 714 climate model ensembles to inform decisions. Philosophical Transactions of the Royal 715 Society A, 365, 2163-177.

716 Stakhiv EZ (2011) Pragmatic approaches for water management under climate change 717 uncertainty. Journal of the American Water Resources Association, 47, 1183-1196.

718 Steinschneider S, Brown C (2013) A semiparametric multivariate, multi-site weather 719 generator with low-frequency variability for use in climate risk assessments. Water Resources 720 Research, 49, 7205-7220.

721 Tisseuil C, Vrac M, Lek S, Wade, AJ (2010) Statistical downscaling of river flows. Journal 722 of Hydrology, 385, 279-291. 
723 Turner, S.W.D., Marlow, D., Ekström, M., Rhodes, B.G., Kularathna, U. and Jeffrey, P.J. 724 2014. Linking climate projections to performance: A yield-based decision scaling assessment 725 of a large urban water resources system. Water Resources Research, 50, 3553-3567.

726 Wang W, Xing W, Shao Q, Yu Z, Peng S, Yang T, Yong B, Taylor J, Singh VP (2013)

727 Changes in reference evapotranspiration across the Tibetan Plateau: Observations and future 728 projections based on statistical downscaling. Journal of Geophysical Research: Atmospheres, 729 118, 4049-4068.

730 Weaver CP, Lempert RJ, Brown C, Hall JA, Revell D, Sarewitz D (2013) Improving the 731 contribution of climate model information to decision making: the value and demands of robust decision frameworks. WIREs Climate Change, 4, 39-60.

733 Whetton P, Hennessy K, Clarke J, McInnes K, Kent D (2012) Use of Representative Climate

734 Futures in impact and adaptation assessment. Climatic Change, 115, 433-442.

735 Wilby RL (2008a) Constructing climate change scenarios of urban heat island intensity and 736 air quality. Environment and Planning B: Planning and Design, 35, 902-919.

737 Wilby RL (2008b) Downscaling future skew surge statistics at Sheerness, Kent. Phase 3 738 studies - synthesis report. Thames Estuary 2100, Environment Agency, 27pp.

739 Wilby RL, Dawson CW (2013) The Statistical DownScaling Model (SDSM): Insights from 740 one decade of application. International Journal of Climatology, 33, 1707-1719.

741 Wilby RL, Dawson CW, Barrow EM (2002) SDSM - a decision support tool for the 742 assessment of regional climate change impacts. Environmental and Modelling Software, 17, $743 \quad 145-157$.

744 Wilby RL, Dessai S (2010) Robust adaptation to climate change. Weather, 65, 180-185.

745 Wilby RL, Harris I (2006) A framework for assessing uncertainties in climate change impacts: 746 low flow scenarios for the River Thames, UK. Water Resources Research, 42, W02419.

747 Wilby RL, Keenan R (2012) Adapting to flood risk under climate change. Progress in $748 \quad$ Physical Geography, 36, 349-379. 
749 Wilby RL, Miller KA, Yates D, Kaatz L (2013) Use of narrative scenarios for evaluating 750 drought management responses in the Upper Colorado River Basin. American Geophysical

751 Union, Fall Meeting 2013, abstract \#H34C-02,

752 Wilby RL, Tomlinson OJ, Dawson CW (2003) Multi-site simulation of precipitation by 753 conditional resampling. Climate Research, 23, 183-194.

754 Wilby RL, Whitehead PG, Wade AJ, Butterfield D, Davis R, Watts G (2006) Integrated 755 modelling of climate change impacts on the water resources and quality in a lowland 756 catchment: River Kennet, UK. Journal of Hydrology, 330, 204-220.

757 Wilby RL, Yu D (2013) Rainfall and temperature estimation for a data sparse region. 758 Hydrology and Earth System Sciences, 17, 3937-3955.

759 Wilby, RL, Hassan H, Hanaki K (1998) Statistical downscaling of hydrometeorological 760 variables using General Circulation Model output. Journal of Hydrology, 205, 1-19.

761 Wilks DS, Wilby RL (1999) The weather generation game: a review of stochastic weather 762 models. Progress in Physical Geography, 23, 329-357.

763 Wise K (2009) Climate-based sensitivity of air quality to climate change scenarios for the 764 southwestern United States. International Journal of Climatology, 29, 87-97.

765 World Bank Independent Evaluation Group (2012) Adapting to Climate Change: Assessing 766 World Bank Group Experience. World Bank Group, Washington DC, 193pp.

767 Yang T, Li H, Wang W, Xu C-Y, Yu Z (2012) Statistical downscaling of extreme daily 768 precipitation, evaporation, and temperature and construction of future scenarios.

769 Hydrological Processes, 26, 3510-3523. 
771 Table 1 Examples of direct downscaling of exotic variables using SDSM

\begin{tabular}{|c|c|c|}
\hline Variable & Location & Source \\
\hline Evaporation & $\begin{array}{l}\text { Haihe, China } \\
\text { Loess plateau, China } \\
\text { Tibetan plateau, Tibet } \\
\text { River Kennet, UK } \\
\text { River Dongjiang, China }\end{array}$ & $\begin{array}{l}\text { Chu et al. (2010) } \\
\text { Li et al. (2012) } \\
\text { Wang et al. (2013) } \\
\text { Wilby et al. (2006) } \\
\text { Yang et al. (2012) }\end{array}$ \\
\hline Ground-level ozone and/or particulates & $\begin{array}{l}\text { Chicago, US } \\
\text { London, UK } \\
\text { Tucson, US }\end{array}$ & $\begin{array}{l}\text { Holloway et al. (2008) } \\
\text { Wilby (2008a) } \\
\text { Wise (2009) }\end{array}$ \\
\hline Heat wave indices & $\begin{array}{l}\text { Mexicali, Mexico } \\
\text { London, UK }\end{array}$ & $\begin{array}{l}\text { Cueto et al. (2010) } \\
\text { Wilby (2007) }\end{array}$ \\
\hline Waves and tidal surge & $\begin{array}{l}\text { North Sea, UK } \\
\text { Isle of Wight, UK } \\
\text { Thames Estuary, UK }\end{array}$ & $\begin{array}{l}\text { Donovan (2003) } \\
\text { Hackney (2013) } \\
\text { Wilby (2008b) }\end{array}$ \\
\hline
\end{tabular}




\section{Cascade of Uncertainty in CMIP5}
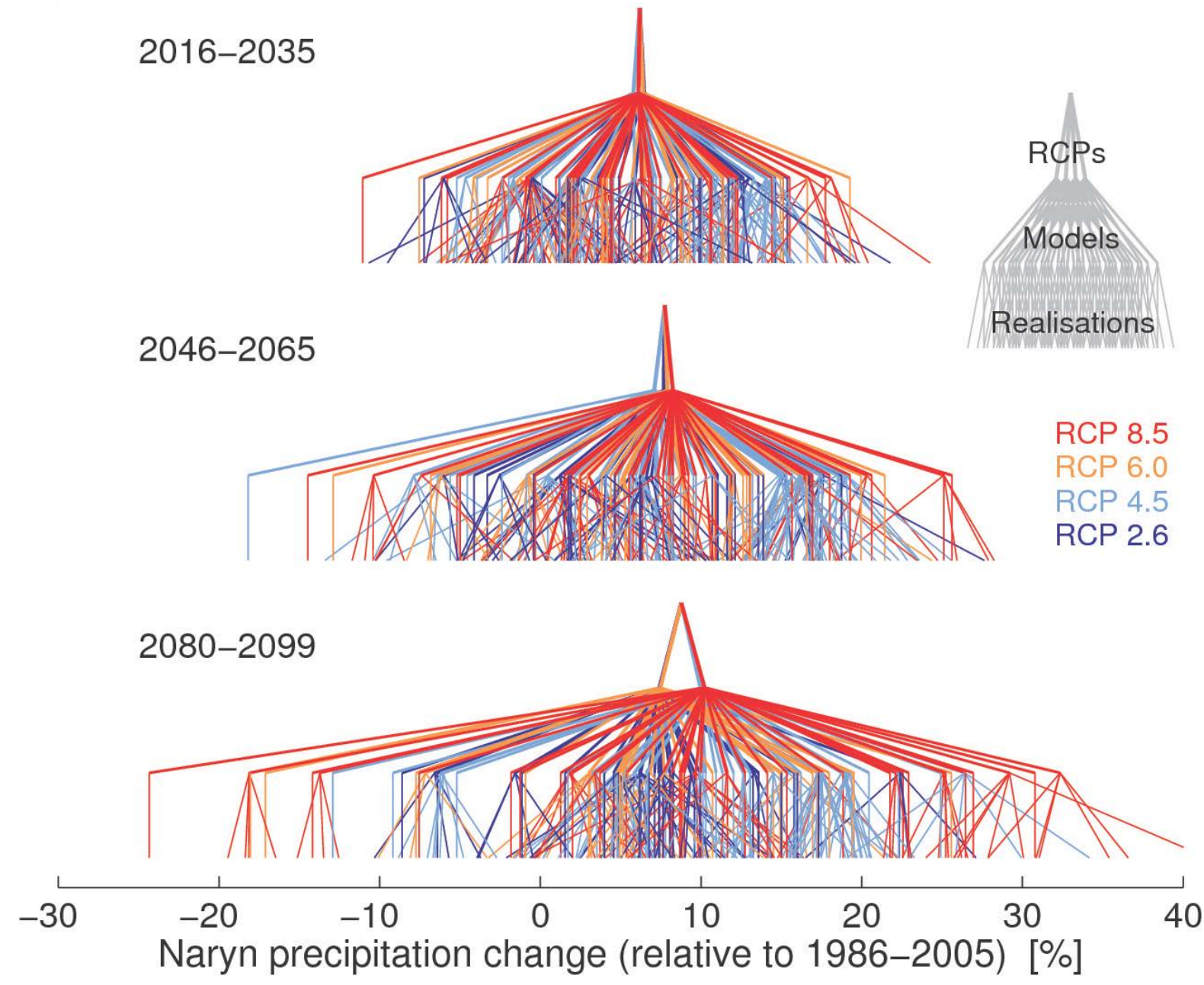

Figure 1 A 'cascade of uncertainty' in precipitation changes projected by the CMIP5 ensemble for the River Naryn basin, Central Asia $\left(70-80^{\circ} \mathrm{E}, 40-45^{\circ} \mathrm{N}\right)$. The three levels of each pyramid illustrate uncertainty due to the choice of Representative Concentration Pathway (RCP), GCM and realisation of climate variability. Not all simulations have multiple realisations, resulting in a vertical line in the lowest layer. The intersection on the top row for each time period is the multi-scenario, multi-model, multi-realisation mean. 
783

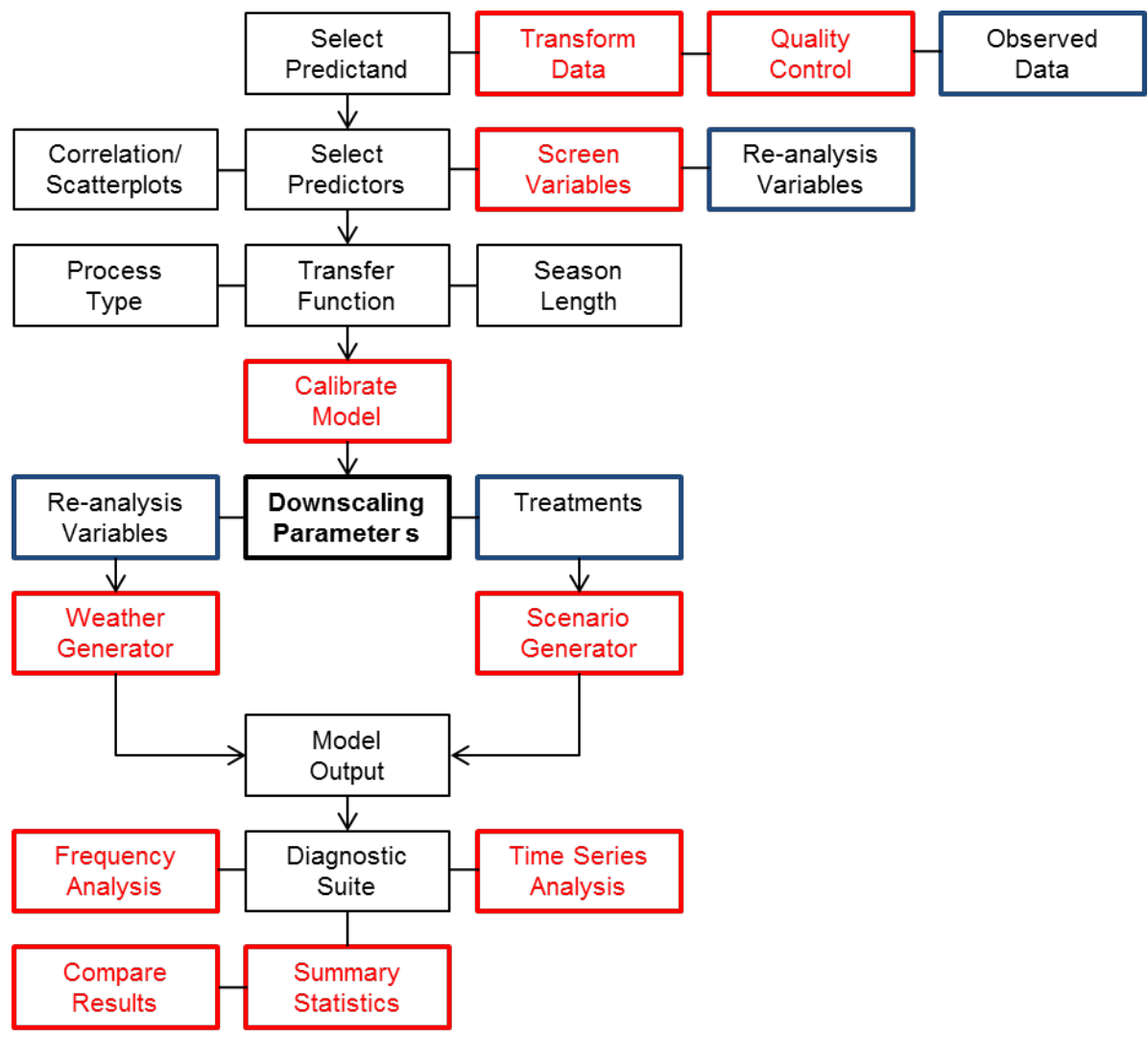

785

786 Figure 2 SDSM-DC architecture showing inputs (blue boxes) and screens (red boxes). 
a)

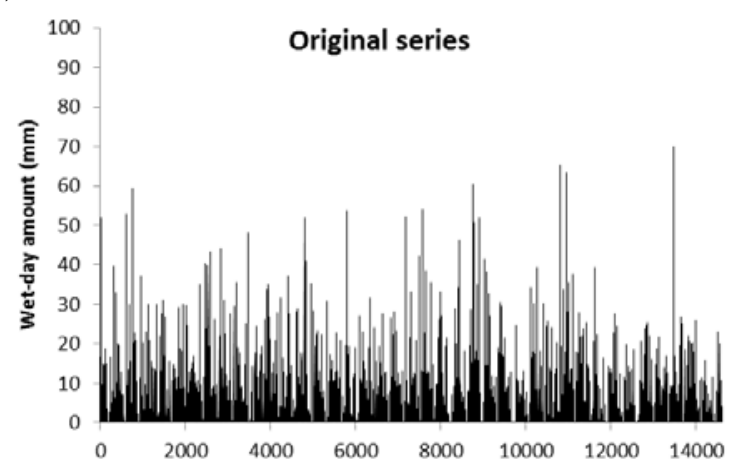

c)

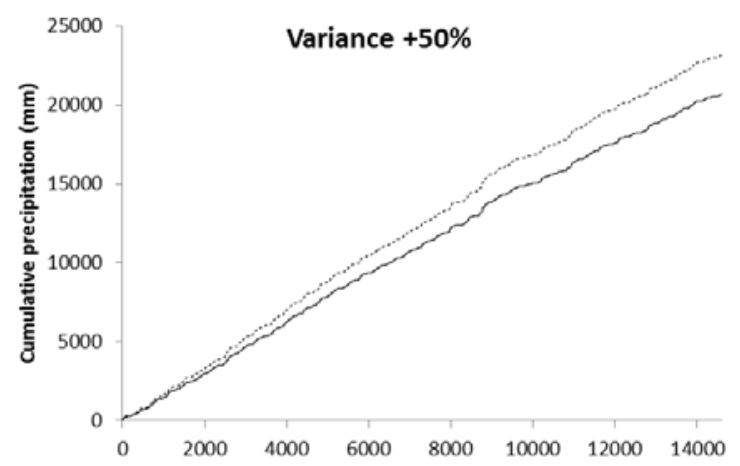

e)

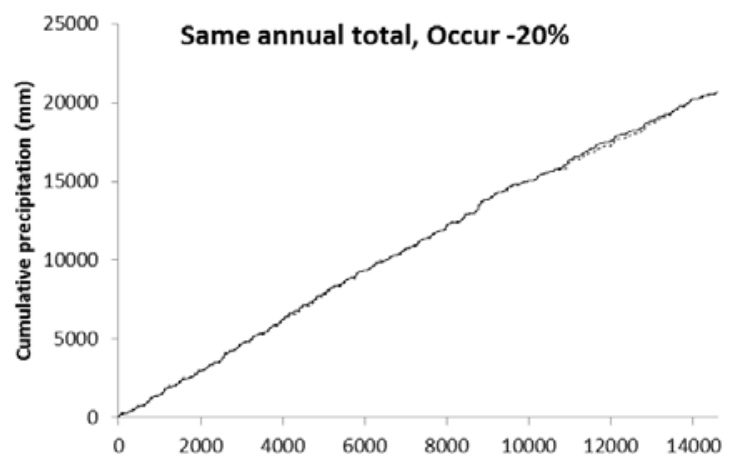

b)

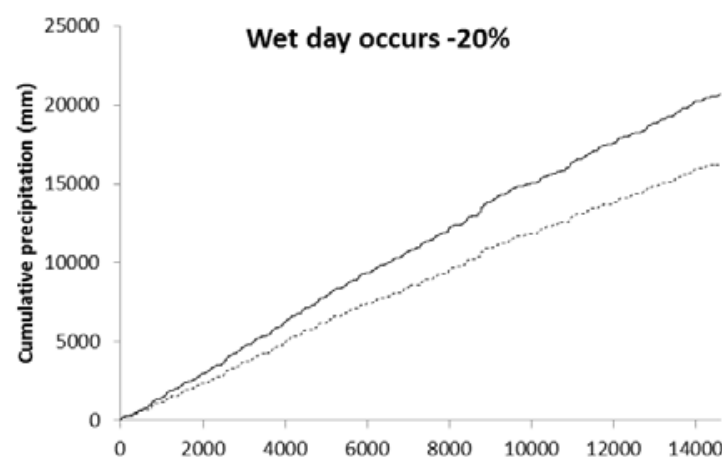

d)

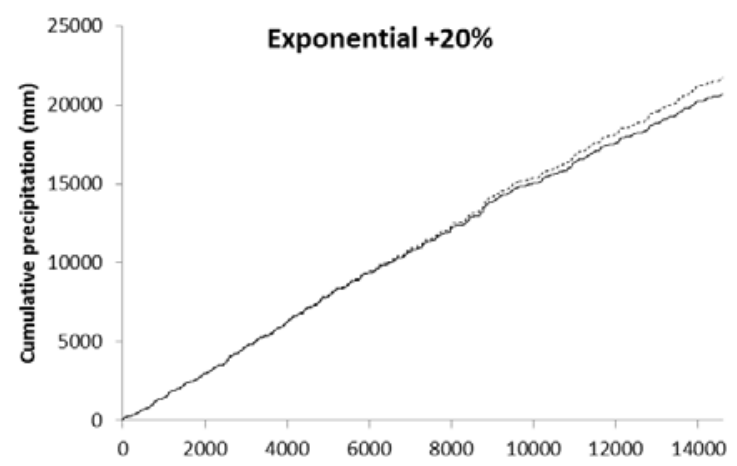

f)

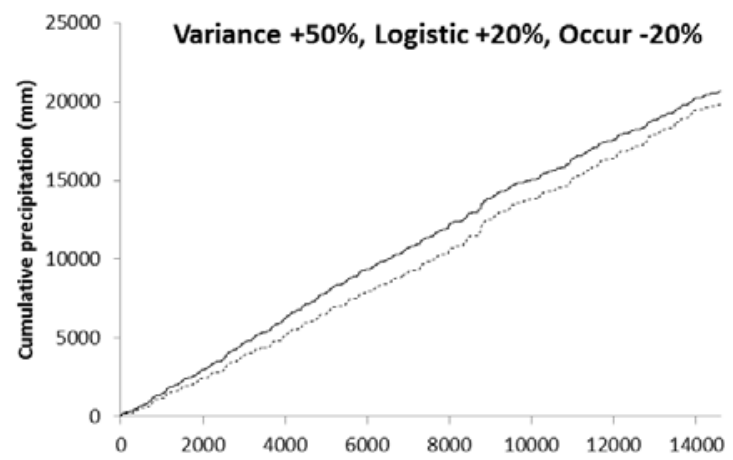

Figure 3 Example SDSM-DC treatments applied to a 40-year daily precipitation series. The dark line shows the original data and the grey line the treated series, both expressed as cumulative totals for ease of comparison. 
794
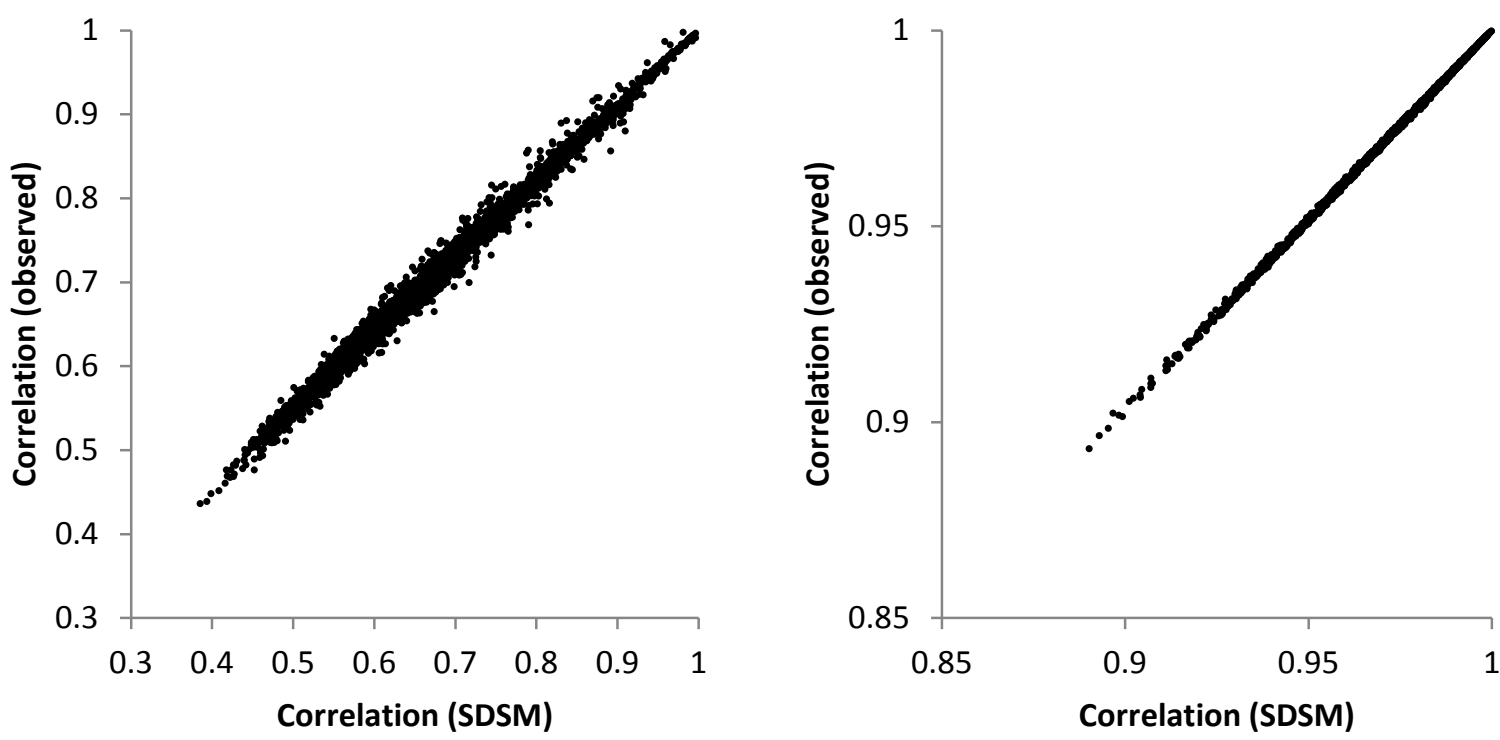

795

796 Figure 4 Pairwise correlation of observed and downscaled daily precipitation (left) and mean 797 temperature (right) in the Upper Colorado River Basin. Source: Wilby et al. (2013). 
799

a) Prince Edward Island (day)

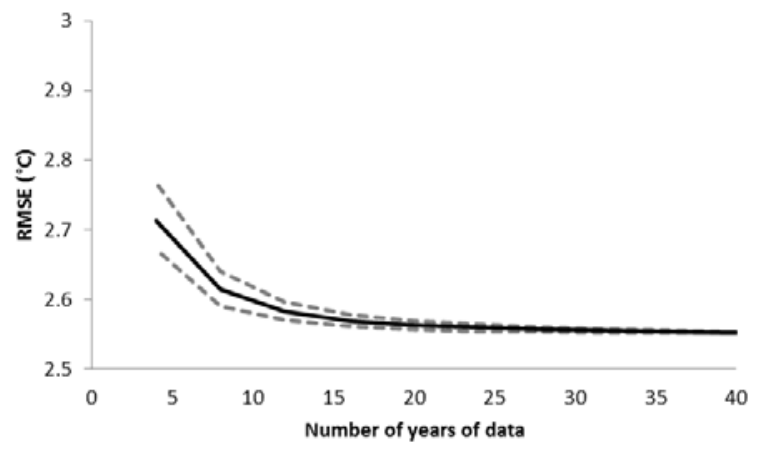

c) Tunis (day)

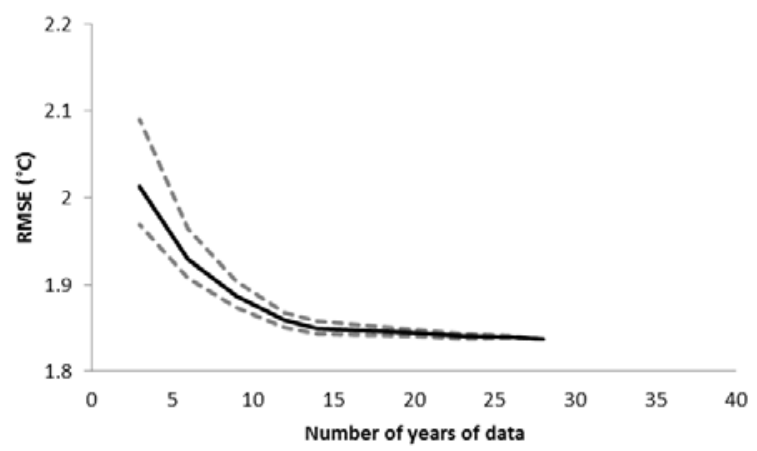

b) Prince Edward Island (year)

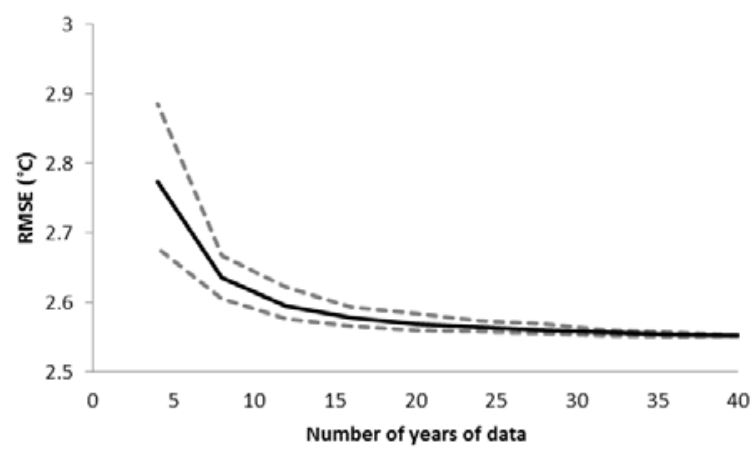

d) Tunis (year)

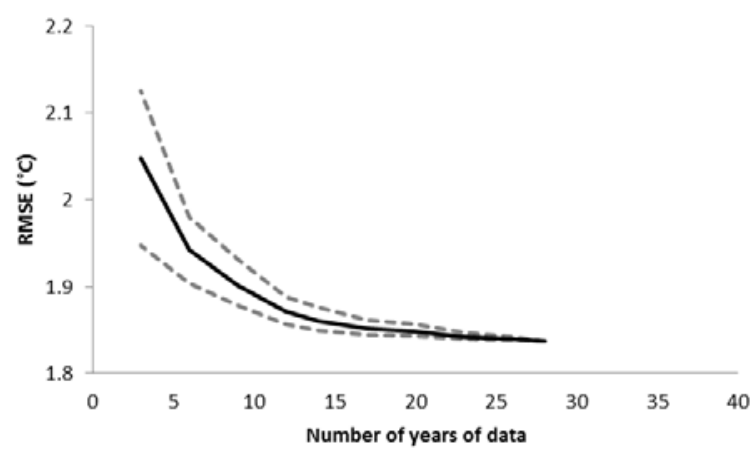

800

801 Figure 5 Effects of missing data on the Root Mean Squared Error (RMSE) of downscaled 802 daily mean temperature depending on whether random days or blocks of years are omitted for 803 a,b) Charlottetown, Prince Edward Island, Canada and for c,d) Tunis, Tunisia. Each plot 804 shows the range (dashed lines) and median (solid line) RMSE based on 100 simulations.

805

806 
807

a) Addis Ababa (day)

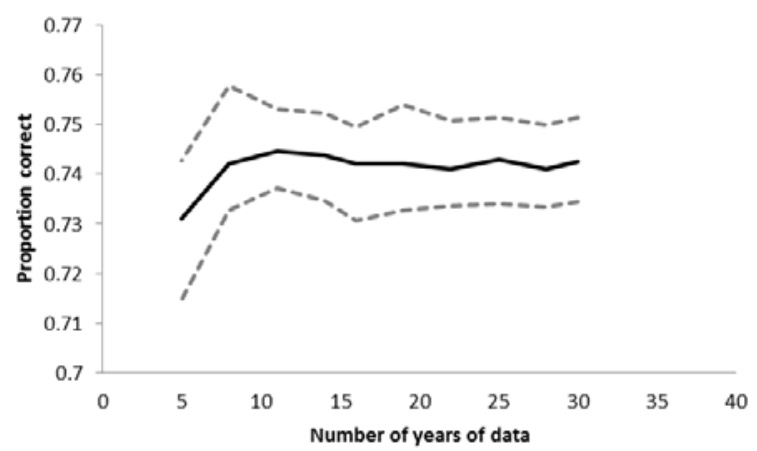

c) Chang wu (day)

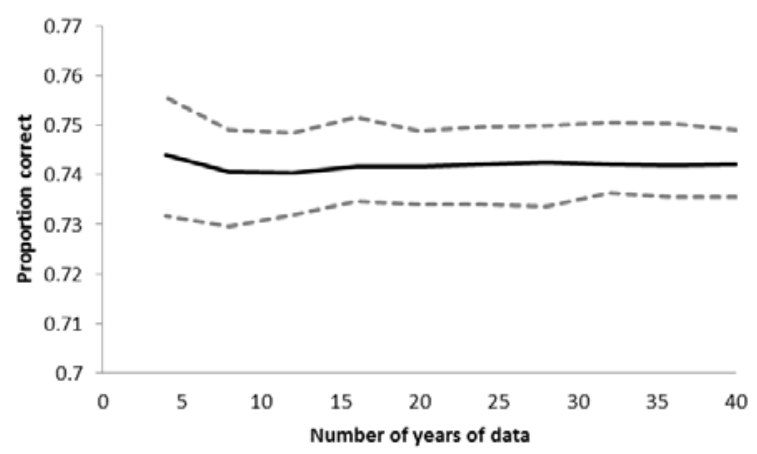

b) Addis Ababa (year)

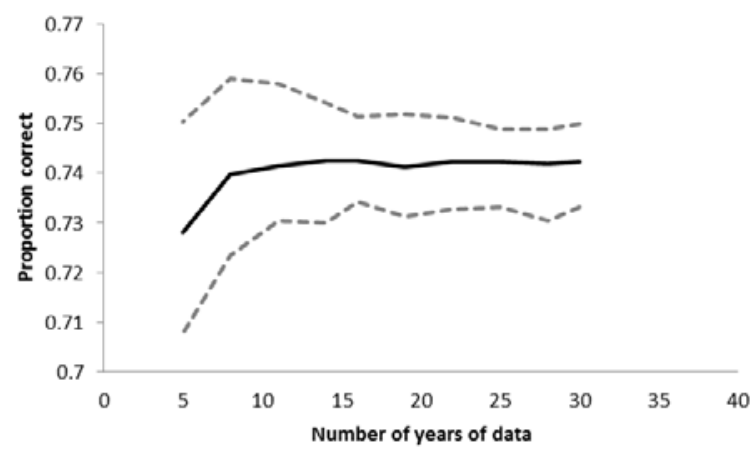

d) Chang wu (year)

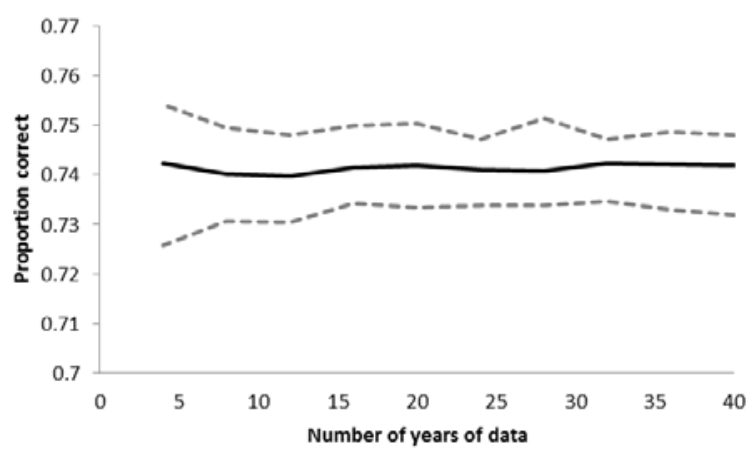

808

809 Figure 6 Effects of missing data on the proportion correct wet-day occurrence (PCW)

810 depending on whether random days or blocks of years are omitted for a,b) Addis Ababa,

811 Ethiopia and for c,d) Chang wu, China.

812

813 
a) Addis Ababa (day)

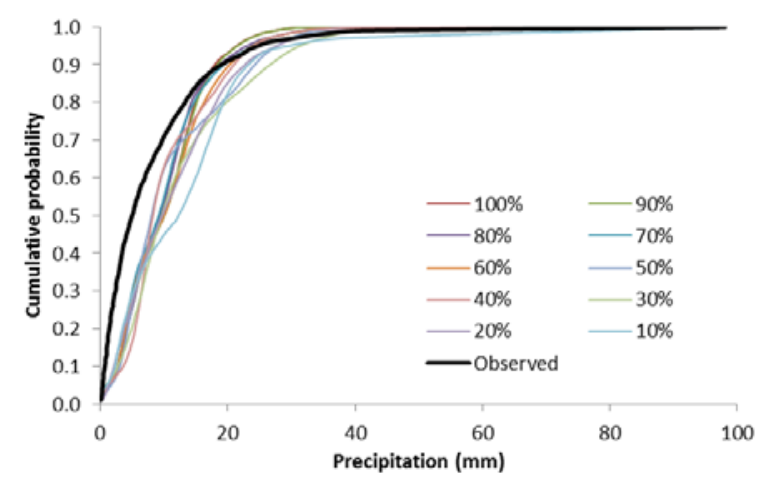

c) Chang wu (day)

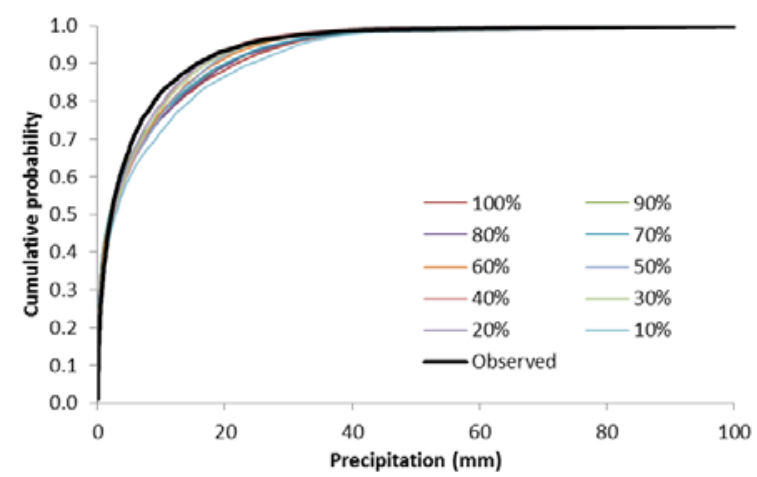

b) Addis Ababa (year)

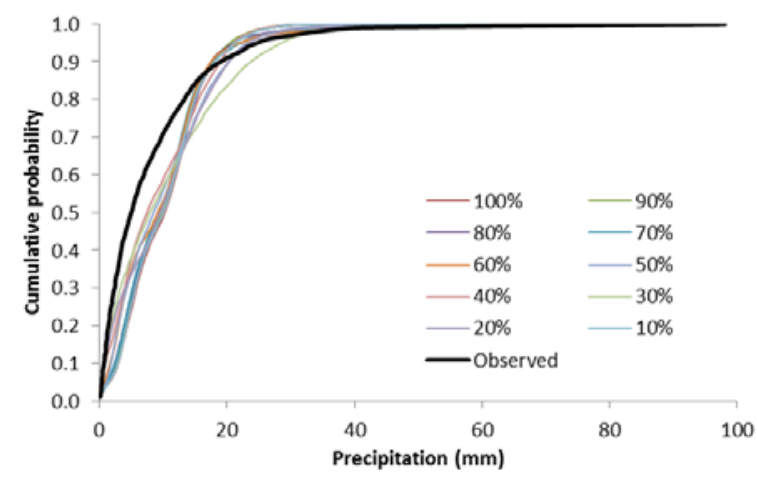

d) Chang wu (year)

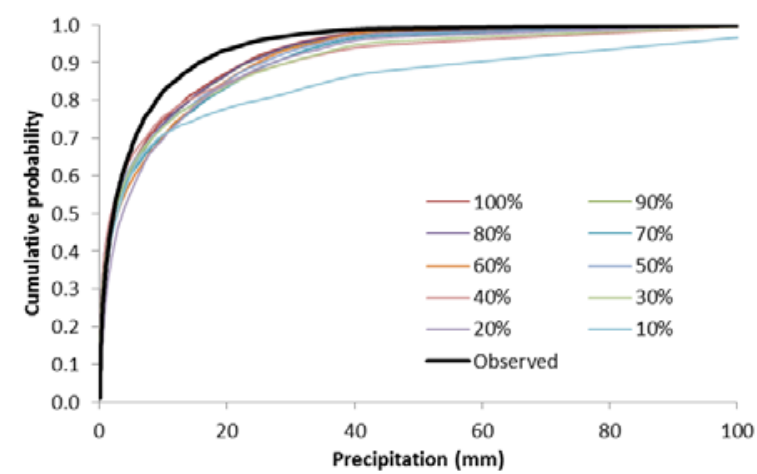

814

815 Figure 7 Sensitivity of downscaled daily precipitation distributions to percent of data omitted 816 by random day (left) or year (right) removal for Addis Ababa (upper) and Chang wu (lower)..

817

818 
a) Addis Ababa (day) [0.8\%]

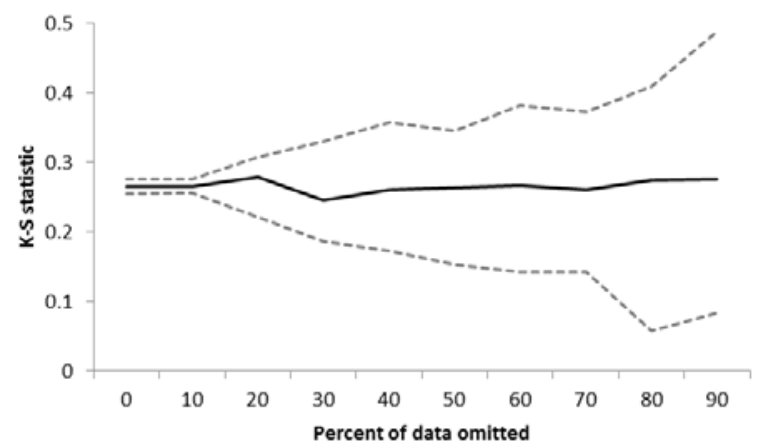

c) Chang wu (day) [22.3\%]

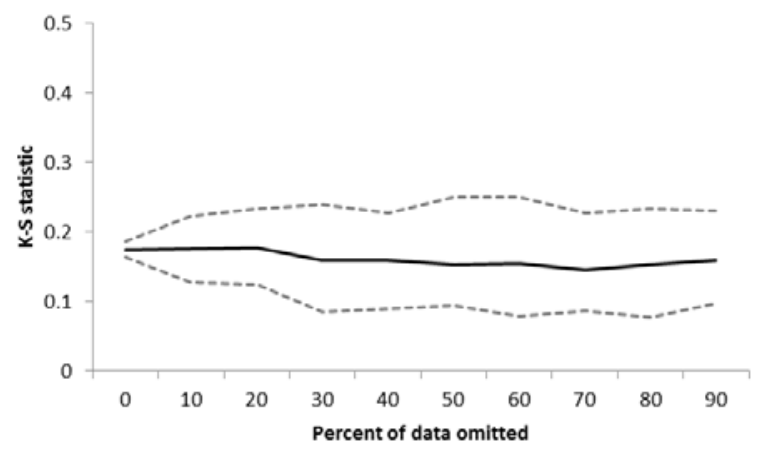

b) Addis Ababa (year) [1.2\%]

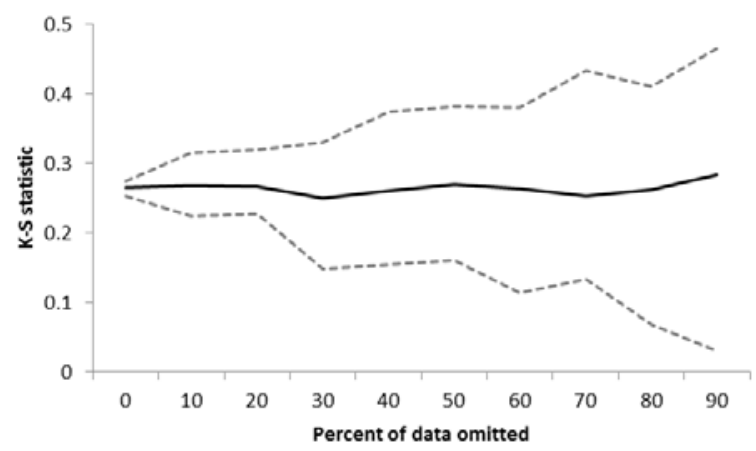

d) Chang wu (year) [22.3\%]

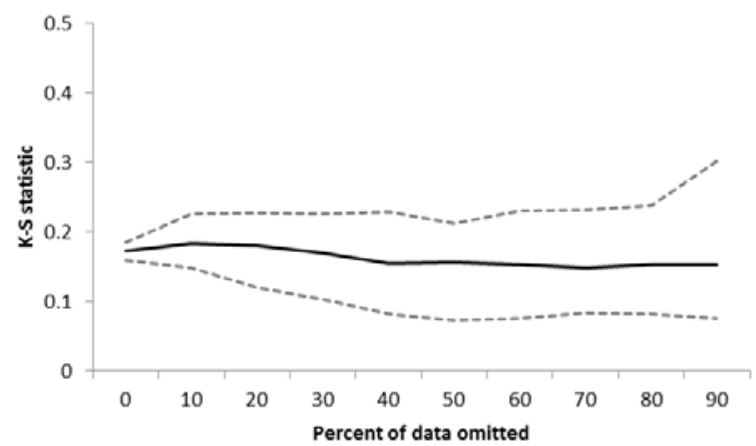

819

820 Figure 8 Sensitivity of the Kolmogorov-Smirnov statistic to percent of data omitted by 821 random day (left) or year (right) removal for Addis Ababa (upper) and Chang wu (lower). 822 The percent of simulations with KS $<$ Dcrit $(0.14$ at $\mathrm{p}=0.05)$ is given [in brackets]. 
824

a) Prince Edward Island (annual daily mean)

b) Prince Edward Island (days $<-10^{\circ} \mathrm{C}$ )
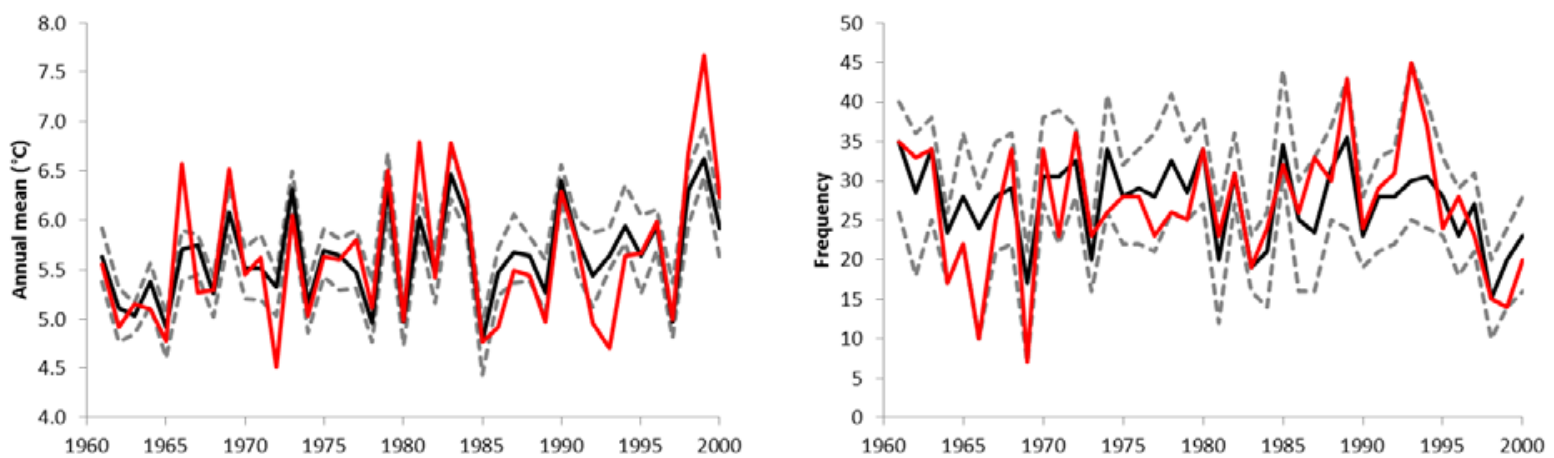

c) Tunis (annual daily maximum)

d) Tunis (days $>35^{\circ} \mathrm{C}$ )
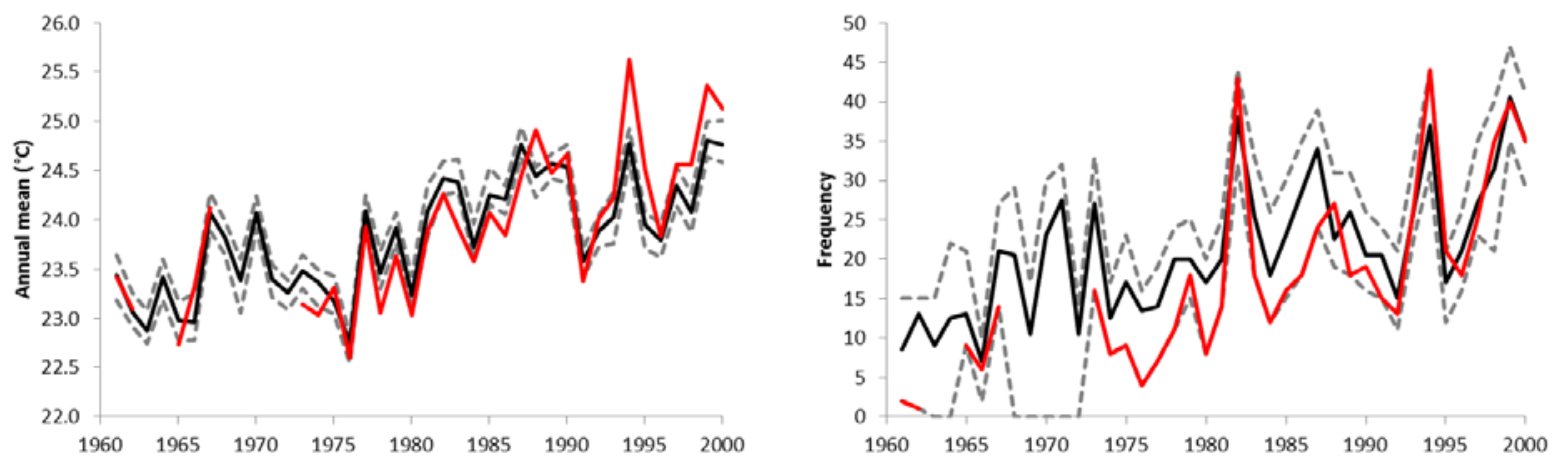

825

826 Figure 9 Reconstructed and in-filled (solid black line) temperatures compared with 827 observations (red line) for a, b) Prince Edward Island, Canada and c,d) Tunis, Tunisia.

828 Dashed lines show the downscaled ensemble range.

829

830

831 
832

a) Addis Ababa (wet-days)

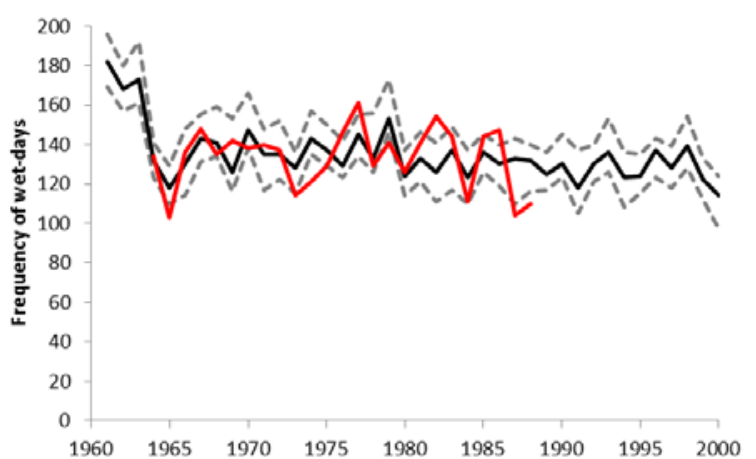

c) Chang wu (wet-days)

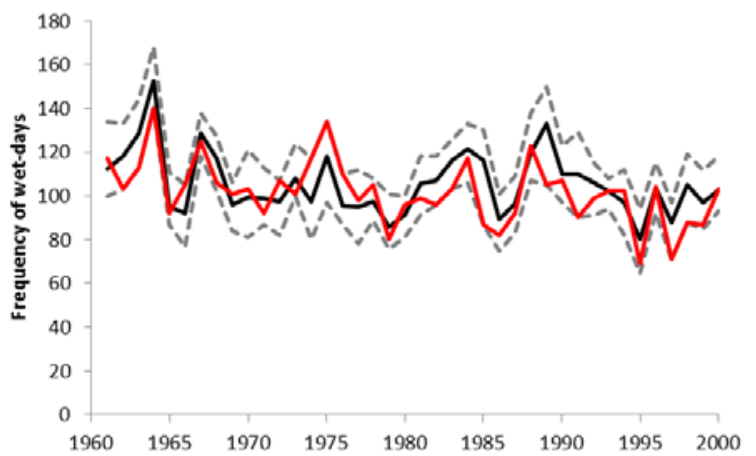

b) Addis Ababa (annual totals)

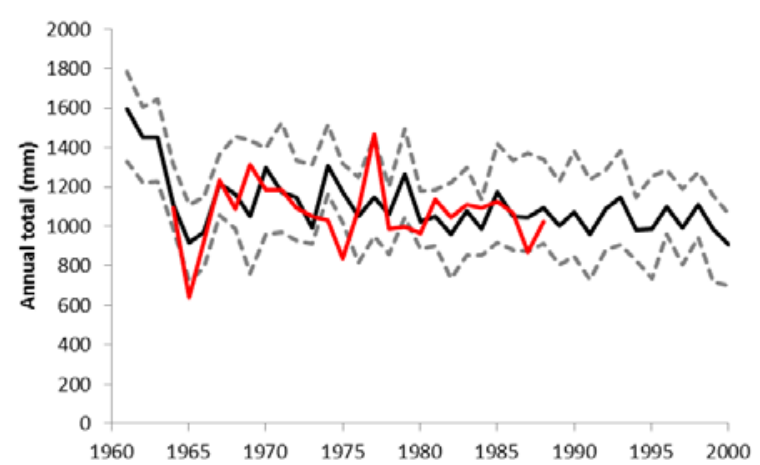

d) Chang wu (annual totals)

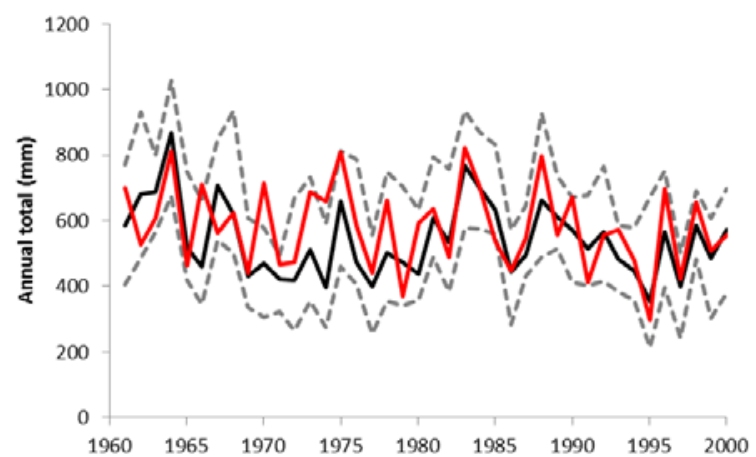

833

834 Figure 10 Reconstructed wet-day frequencies and annual precipitation totals for a,b) Addis 835 Ababa, Ethiopia and c,d) Chang wu, China.

836

837 
838

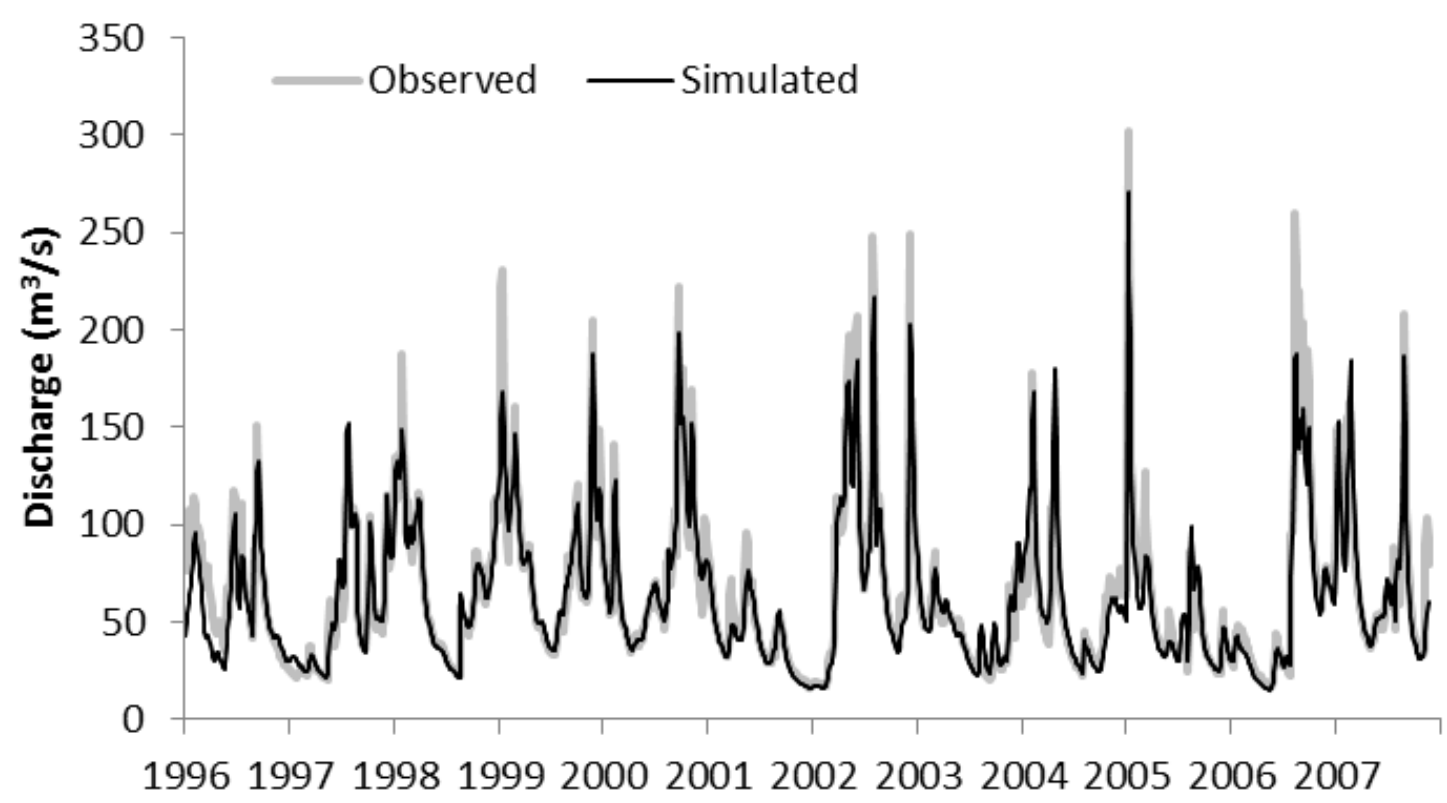

839

840 Figure 11 Comparison of observed (grey line) and HYSIM (black line) simulations of winter 841 daily flows in the River Boyne for the verification period 1997-2007.

842 


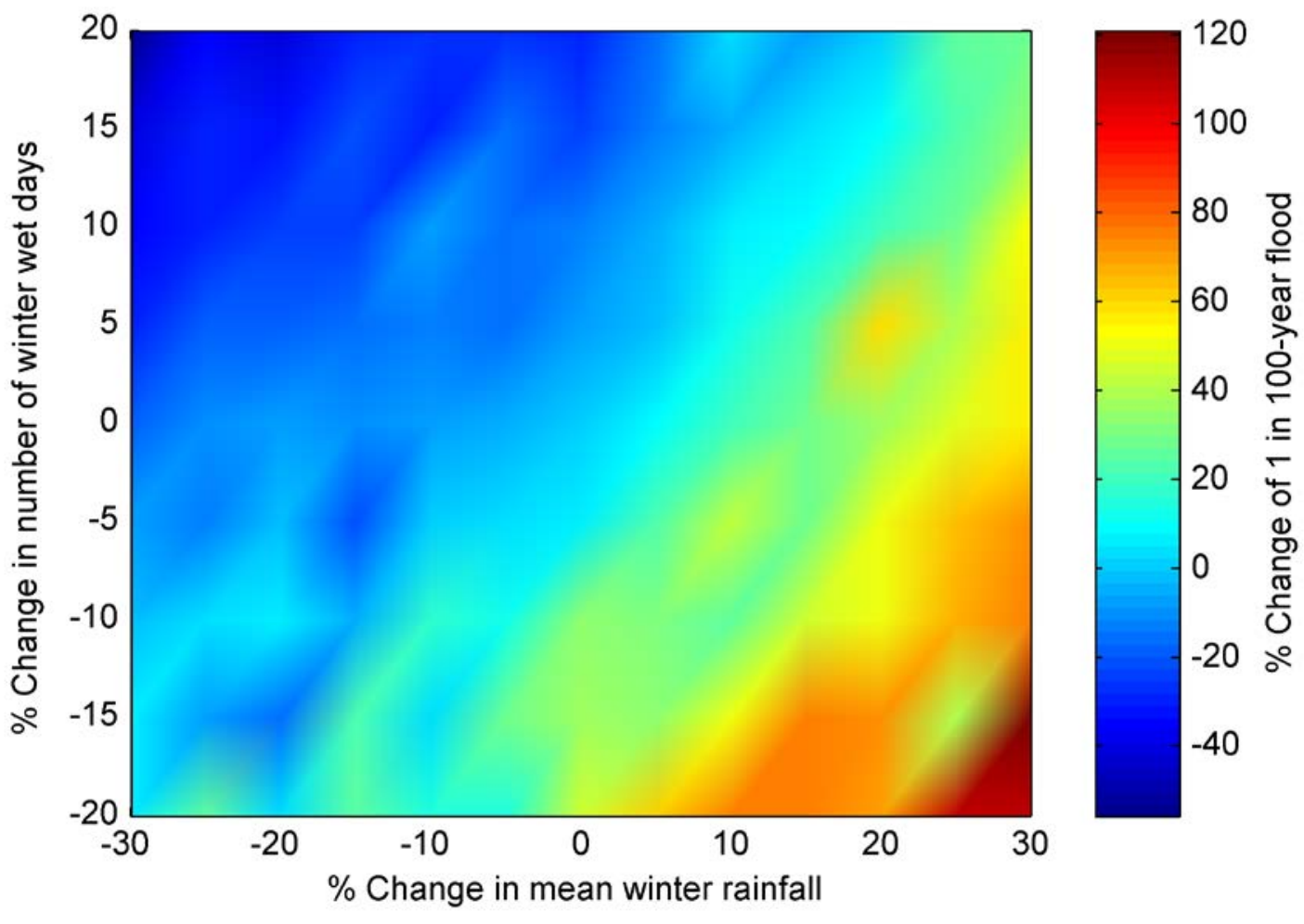

844 Figure 12 Response surface representing the sensitivity of percent changes in the magnitude 845 of the winter 1-in-100 year flood to changes in mean winter rainfall and occurrence of winter 846 wet days. 
849
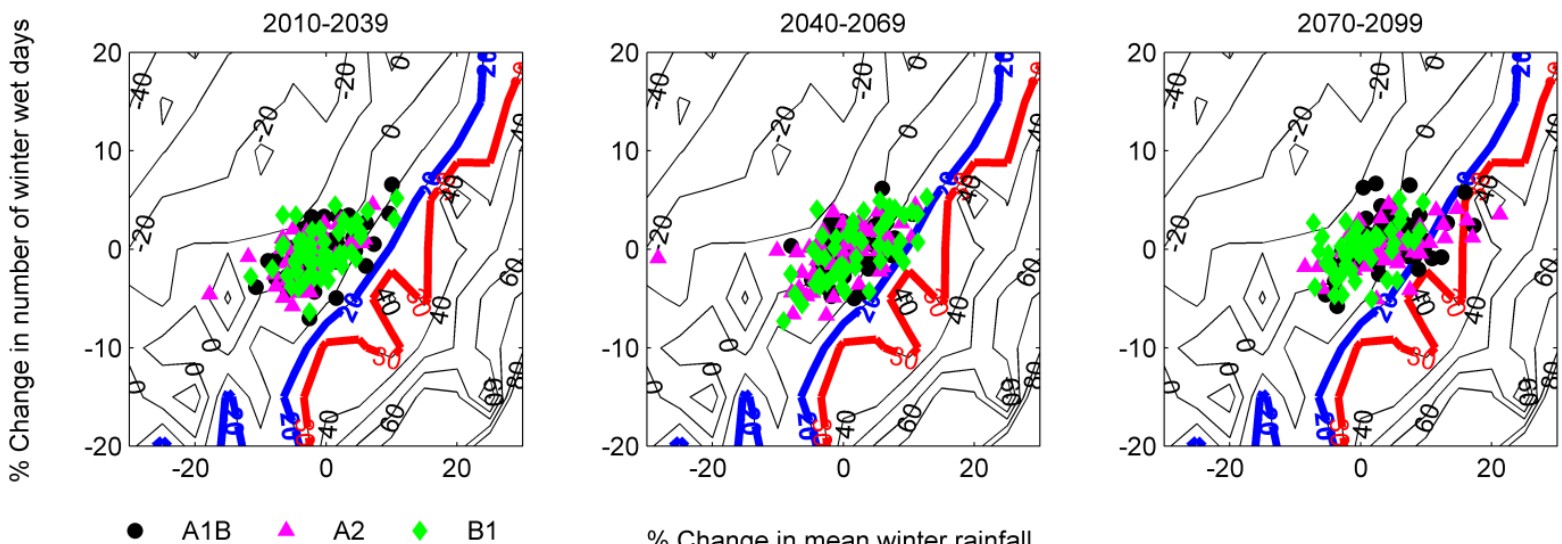

850

$\%$ Change in mean winter rainfall

851 Figure 13 Sensitivity of precautionary allowances to projected changes in climate during

852 winter months (DJF). Contours representing allowances of an additional 20 and $30 \%$ of

853 design flow (1-in-100 year flood) are highlighted in blue and red respectively. Climate

854 change projections (Bastola et al., 2011) represent a sample of 17 GCMs from the CMIP3

855 project forced with the A1B, A2 and B1 SRES emissions scenarios for the 2020s (2010-39),

856 2050s (2040-69) and 2080s (2070-99).

857

858

859 